\title{
BROOKHFWEN
}

NATIONAL LABORATORY

BNL-99145-2013-IR

\section{Local Burn-Up Effects in the NBSR Fuel Element}

\author{
N.R. Brown, A.L. Hanson, D.J. Diamond
}

January 2013

\author{
Nuclear Science \& Technology Department \\ Brookhaven National Laboratory
}

\section{National Institute of Standards and Technology National Nuclear Security Administration}

Notice: This manuscript has been authored by employees of Brookhaven Science Associates, LLC under Contract No. DE-AC02-98CH10886 with the U.S. Department of Energy. The publisher by accepting the manuscript for publication acknowledges that the United States Government retains a non-exclusive, paid-up, irrevocable, world-wide license to publish or reproduce the published form of this manuscript, or allow others to do so, for United States Government purposes. 


\section{DISCLAIMER}

This report was prepared as an account of work sponsored by an agency of the United States Government. Neither the United States Government nor any agency thereof, nor any of their employees, nor any of their contractors, subcontractors, or their employees, makes any warranty, express or implied, or assumes any legal liability or responsibility for the accuracy, completeness, or any third party's use or the results of such use of any information, apparatus, product, or process disclosed, or represents that its use would not infringe privately owned rights. Reference herein to any specific commercial product, process, or service by trade name, trademark, manufacturer, or otherwise, does not necessarily constitute or imply its endorsement, recommendation, or favoring by the United States Government or any agency thereof or its contractors or subcontractors. The views and opinions of authors expressed herein do not necessarily state or reflect those of the United States Government or any agency thereof. 


\section{Local Burn-Up Effects in the NBSR Fuel Element}

Manuscript Completed:

January 23, 2013

Prepared by:

N. R. Brown, A. L. Hanson, and D. J. Diamond

Nuclear Science \& Technology Department

Brookhaven National Laboratory

Upton, NY 11973-5000

Prepared for:

National Institute of Standards and Technology

National Nuclear Security Administration 



\begin{abstract}
This study addresses the over-prediction of local power when the burn-up distribution in each halfelement of the NBSR is assumed to be uniform - a constraint in the full core model used for neutronic analysis. A single-element model was utilized to quantify the impact of axial and plate-wise burn-up on the power distribution within the NBSR fuel elements for both high-enriched uranium (HEU) and lowenriched uranium (LEU) fuel. To validate this approach, key parameters in the single-element model were compared to parameters from an equilibrium core model, including neutron energy spectrum, power distribution, and integral U-235 vector. The power distribution changes significantly when incorporating local burn-up effects and has lower power peaking relative to the uniform burn-up case. In the uniform burn-up case, the axial relative power peaking is over-predicted by as much as 59\% in the HEU singleelement and $46 \%$ in the LEU single-element with uniform burn-up. In the uniform burn-up case, the plate-wise power peaking is over-predicted by as much as $23 \%$ in the HEU single-element and $18 \%$ in the LEU single-element. The degree of over-prediction increases as a function of burn-up cycle, with the greatest over-prediction at the end of Cycle 8. The thermal flux peak is always in the mid-plane gap; this causes the local cumulative burn-up near the mid-plane gap to be significantly higher than the fuel element average. Uniform burn-up distribution throughout a half-element also causes a bias in fuel element reactivity worth, due primarily to the neutronic importance of the fissile inventory in the midplane gap region.
\end{abstract}




\section{Table of Contents}

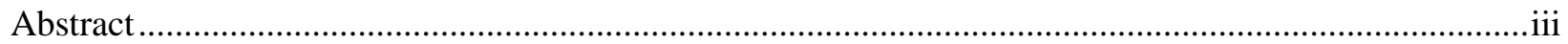

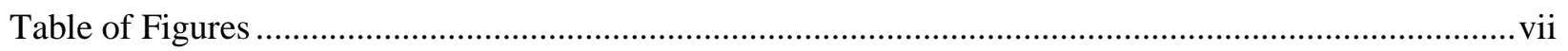

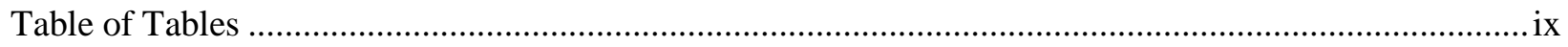

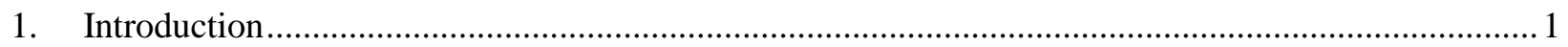

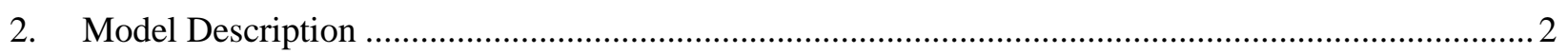

3. Assessment of the Single-Element Model .......................................................................

4. Axial Power Distributions as a Function of Burn-Up ....................................................... 12

5. Plate-Wise Power Distributions as a Function of Burn-Up ...................................................22

6. Reactivity Effects of Uneven Burn-Up ..........................................................................29

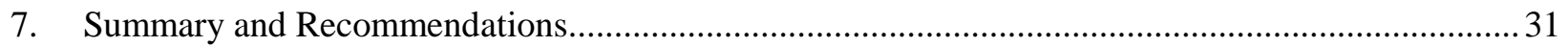

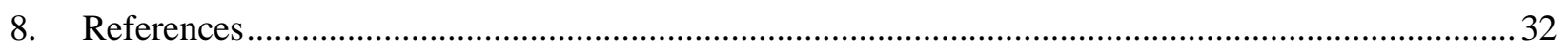

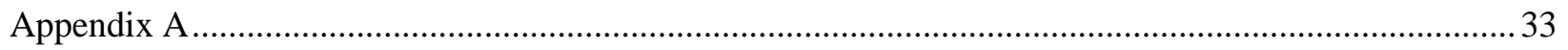

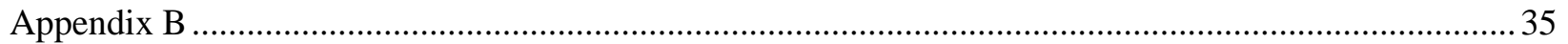

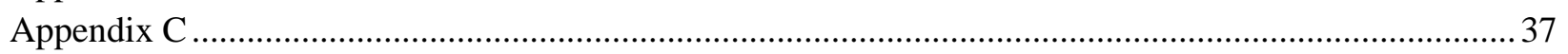




\section{List of Figures}

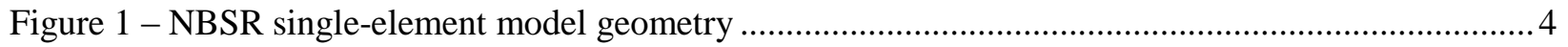

Figure 2 - Elevation views of the mid-plane gap and the burn-up zones in the axial burn-up model.......... 5

Figure 3 - Definition of the plate numbering scheme in the plate-wise burn-up model............................ 6

Figure 4 - Neutron energy spectrum in the mid-plane gap................................................................ 7

Figure 5 - Axial power distributions in the HEU NBSR (element A-4) vs. the single-element model ....... 8

Figure 6 - Axial power distributions in the LEU NBSR (element A-4) vs. the single-element model ........ 9

Figure 7 - Plate-to-plate power in the NBSR (element A-4 at SU) vs. the single-element model ..............9

Figure 8 - Mass of U-235 per element as a function of cycle for HEU single-element and NBSR ........... 10

Figure 9 - Mass of Pu-239 per element as a function of cycle for HEU single-element and NBSR .......... 10

Figure 10 - Mass of U-235 per element as a function of cycle for LEU single-element and NBSR ..........11

Figure 11 - Mass of Pu-239 per element as a function of cycle for the LEU single-element and NBSR ... 11

Figure 12 - Single-element HEU axial power distributions assuming uniform burn-up......................... 14

Figure 13 - Single-element HEU axial power distributions assuming axially variant burn-up ................. 14

Figure 14 - Single-element HEU axially variant-to-uniform power ratio................................................ 15

Figure 15 - HEU cumulative burn-up at EOC $(\mathrm{GWd} / \mathrm{t})$ as a function of cycle ....................................... 15

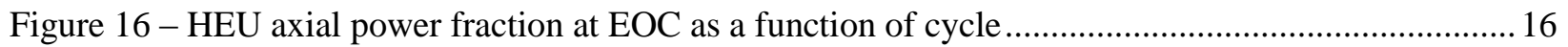

Figure 17 - HEU cumulative burn-up at EOC $(\mathrm{GWd} / \mathrm{t})$ per axial power fraction ..................................... 16

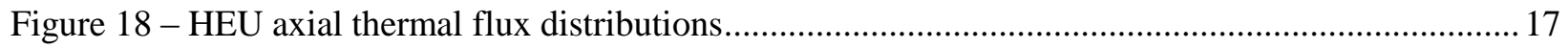

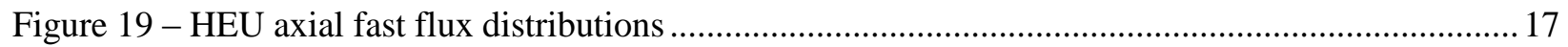

Figure 20 - Single-element LEU axial power distributions assuming uniform burn-up............................ 18

Figure 21 - Single-element LEU axial power distributions assuming axially variant burn-up.................. 18

Figure 22 - Single-element LEU axially variant-to-uniform power ratio ................................................ 19

Figure 23 - LEU cumulative burn-up at EOC $(\mathrm{GWd} / \mathrm{t})$ as a function of cycle ......................................... 19

Figure 24 - LEU axial power fraction at EOC as a function of cycle .....................................................22

Figure 25 - LEU cumulative burn-up at EOC $(\mathrm{GWd} / \mathrm{t})$ per axial power fraction ...................................20

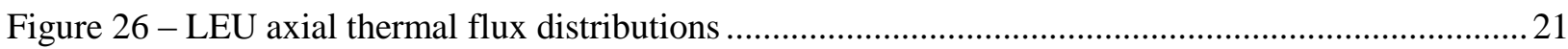

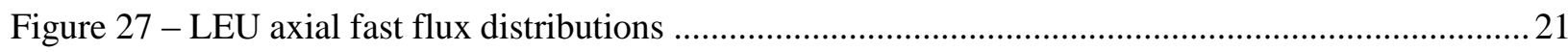

Figure 28 - Single-element HEU plate-wise power distributions assuming uniform burn-up ................. 23

Figure 29 - Single-element HEU plate-wise power distributions assuming plate-wise burn-up ...............23

Figure 30 - Single-element HEU plate-wise burn-up factor ...............................................................24

Figure 31 - HEU cumulative plate-wise burn-up at EOC $(\mathrm{GWd} / \mathrm{t})$ as a function of cycle .......................24

Figure 32 - HEU plate-wise power fraction at EOC as a function of cycle .............................................25

Figure 33 - HEU cumulative burn-up at EOC $(\mathrm{GWd} / \mathrm{t})$ per plate-wise power fraction .............................25

Figure 34 - Single-element LEU plate-wise power distributions assuming uniform burn-up ....................26

Figure 35 - Single-element LEU plate-wise power distributions assuming plate-wise burn-up.................26

Figure 36 - Single-element LEU plate-wise burn-up factor................................................................2

Figure 37 - LEU cumulative plate-wise burn-up at EOC $(\mathrm{GWd} / \mathrm{t})$ as a function of cycle .........................22

Figure 38 - LEU plate-wise power fraction at EOC as a function of cycle ...........................................28

Figure 39 - LEU cumulative burn-up at EOC $(\mathrm{GWd} / \mathrm{t})$ per plate-wise power fraction ............................28

Figure 40 - Reactivity difference of the uniform burn-up case and the axial burn-up case ......................29

Figure 41 - Reactivity difference of the uniform burn-up case and the plate-wise burn-up case ............... 30 


\section{List of Tables}

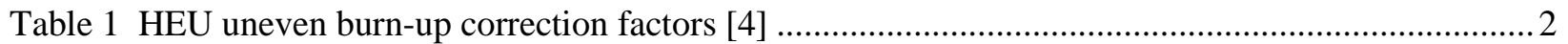




\section{Introduction}

The National Institute of Standards and Technology research reactor (NBSR) is considering a conversion from high-enriched uranium (HEU) fuel to low-enriched uranium (LEU) fuel. This requires analysis of the utilization of LEU fuel with respect to the following goals: (1) verification of the continued safety of the reactor system, and (2) understanding of the impact on the experimental mission of the reactor. Local power peaking is a key parameter but is over-predicted due to the modeling of uniform burn-up in each half-element. In the present study, the impact of uneven fuel burn-up in the fuel elements is considered with a simplified single-element (SE) model.

For the conversion of the reactor to LEU fuel, an improved full-core model of the NBSR has been recently developed for the neutronic and burn-up analysis [1]. This improved model, henceforth referred to as the present model, utilizes MCNPX [2] to accomplish a detailed burn-up analysis where each halfelement has a unique fuel inventory (material composition) that is moved throughout the core in the correct fuel shuffling scheme [3]. This is in contrast to the NBSR model utilized in the 2010 Safety Analysis Report (SAR) [4], where numerous simplifying assumptions were necessitated. Some of the improvements made to the burn-up analysis in the present full-core model include [3]:

- reduction in unaccounted mass from $\sim 1.2 \%$ per cycle per fuel element [4] to $\sim 0.13 \%$ per cycle per fuel element,

- increase of the number of isotopes considered from a maximum of 63 to a maximum of 210 ,

- increase of the number of fuel inventories from 30 to 60 eliminating forced symmetry radially, in the half fuel elements' material compositions,

- inclusion of the 10.5-day decay time at the end of each cycle,

- analysis of additional burn-up state points,

- utilization of the ENDF-B/VII.0 cross section libraries,

- and realistic positioning of the shim arms (control elements) within each burn-up state point.

There are still some simplifications to the burn-up analysis that are made in the present full-core model. Within each half-element the fuel compositions are assumed constant. There are several reasons for this simplification. It is computational expensive to include a detailed mesh for each half-element that accounts for the axial and plate-to-plate variation of the burn-up. There is also the problem of the local variance in the calculated reaction rates. MCNPX utilizes the Monte Carlo method to solve the neutron transport equation and thus the statistical quality of the local interaction rate is partially dependent on the number of interactions in each cell. In the present full-core model it is difficult to attain uniform convergence of the local interaction tallies. Thus, the statistical quality of the local inventories in a high burn-up region will be greater than the statistical quality of the inventories in a low burn-up region. The local neutron flux in the NBSR core can vary by several orders of magnitude (e.g. near control elements) [5]. By considering uniform fuel inventories in each half-element these local complications are eliminated.

Determination of the local power distribution from uniform inventories for each half-element yields hot spot factors that are artificially high [4]. In the extremities of the fuel elements, where the thermal 
neutron flux tends to peak, the fuel will actually be significantly depleted at the end-of-life. The use of integral fuel compositions to determine the local power effectively constitutes a re-distribution of fissile material in the fuel element at each burn-up step. This error in the local power is compounded with each cycle and will result in prediction of a hot spot that is unrealistic. In reality, the hot spots are reduced as the fissile material in these regions is consumed more rapidly due to uneven burn-up. This uneven burnup yields a relatively even distribution of heat generation throughout the fuel element [4]. There are other important effects of uneven burn-up. For example, the reactivity worth of the individual fuel elements is biased by the homogenization in the material inventories.

In the NBSR SAR, a simplified method was utilized to account for uneven burn-up in the fuel elements [4]. The relevant information from Reference [4] is reproduced in Appendix A. The uneven burn-up correction factors utilized in the SAR are summarized in Table 1.

Table 1 HEU uneven burn-up correction factors [4]

\begin{tabular}{|c|c|}
\hline One cycle & 0.900 \\
\hline Two cycles & 0.846 \\
\hline $\begin{array}{c}\text { Three or more } \\
\text { cycles }\end{array}$ & 0.779 \\
\hline
\end{tabular}

The present analysis advances understanding of uneven fuel burn-up in the NBSR fuel elements. The NBSR fuel element design is unique, primarily due to the unfuelled gap at the axial mid-plane where the thermal flux peaks and low energy neutrons stream to the beam ports and cold sources. The objective of this study is to quantify the impact of the unfuelled mid-plane gap and the plate-to-plate self-shielding on the burn-up and power distributions in the NBSR fuel element. To accomplish this, a single-element model is utilized in several depletion calculations to assess the impact of the mid-plane gap (on axial distributions) and plate-to-plate self-shielding (on plate-wise distributions). This analysis is performed for both the HEU and LEU fuel.

The single-element model results are compared to the full core model in terms of the neutron energy spectrum in the mid-plane gap, the axial fuel element power distributions for a fresh element, the plate-toplate power distribution for a fresh element, and the U-235/Pu-239 inventories as a function of element burn-up. These validation studies yield a strong basis for using the single-element model as a tool for quantification of the conservatism of the fuel element power distribution in the full-core model.

\section{Model Description}

The single-element model utilized in this work is derived from the full core MCNP model of the NBSR [1] and is shown in Figure 1. The single-element model consists of two half-elements. The height of the model is $120 \mathrm{~cm}$, with an equal amount of heavy water "reflector" above/below each half element. The axial center of the model is the mid-plane gap. A planar view of the bottom half-element, $15 \mathrm{~cm}$ below the mid-plane gap, is also shown in Figure 1. The grid plates and shim arms (control elements) are not included in the model. Other than these omissions, the single-element model is identical to the model of a fuel element in the full-core NBSR model. The mid-plane gap, filled with heavy water moderator, is 
where the thermal flux peaks, and is perhaps the most unique neutronic feature of the NBSR. The midplane gap is shown in Figure 2.

A periodic boundary condition is applied to the outer surfaces of the hexagonal unit cell, and a "black" boundary condition is applied to the axially bounding surfaces of the geometry. Both the top and bottom half-elements are included in the present model. This inclusion was made to verify the symmetry of the results and thus the efficacy of the model. The axial upper and lower reflector heights are symmetric about the horizontal mid-plane. Adjustment of the axial reflector height (e.g. axial leakage) could be utilized as a surrogate loss term to adjust the axial power distributions in the model.

Figure 2 shows an elevation view with the axial discretization of the geometry in the single-element model. For the study of axially variant burn-up, each half-element is decomposed into 14 axial cells. These axial cells span all 17 plates in each half-element. Axially symmetric cells share a material composition, so there are 14 fuel materials in the model. These are illustrated as different colors in Figure 2. It should be noted that the colors in Figure 2 repeat every 10 materials. The axial power mesh is identical to that used in the full-core model $(\sim 2 \times 2 \mathrm{~cm}$ mesh). Thus, the power distributions from this model may be directly compared to the power distributions in the full-core model.

A plate-wise burn-up model is also considered separately. . Due to symmetry of the upper and lower halfelements in the single-element model as well as east-west symmetry of the fuel plates, only nine platewise cells and corresponding fuel materials are required to uniquely consider all 34 fuel plates in a singleelement. The plate-wise burn-up zones are shown in Figure 3.

The dominant effect studied in the axially variant burn-up single-element model is the impact of the midplane gap, which fixes the axial location of the thermal flux peak in the fuel element. The significant neutronic effects studied with the plate-wise variant burn-up model are the plate-to-plate self shielding and the thermal flux peaking on the exterior of the fuel element. 


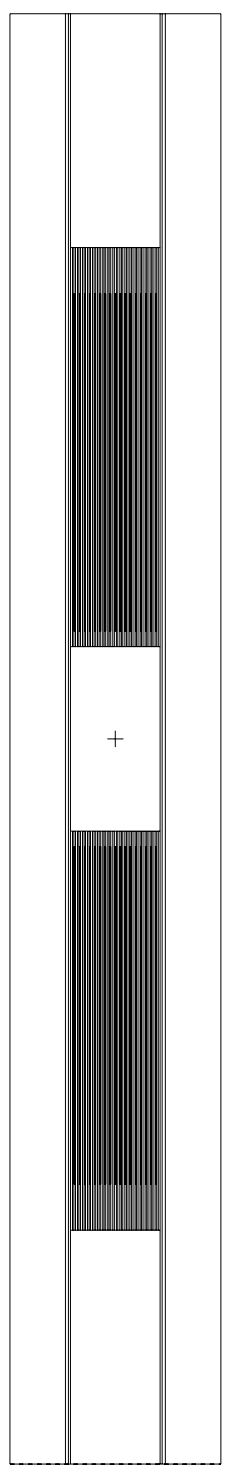

Elevation view

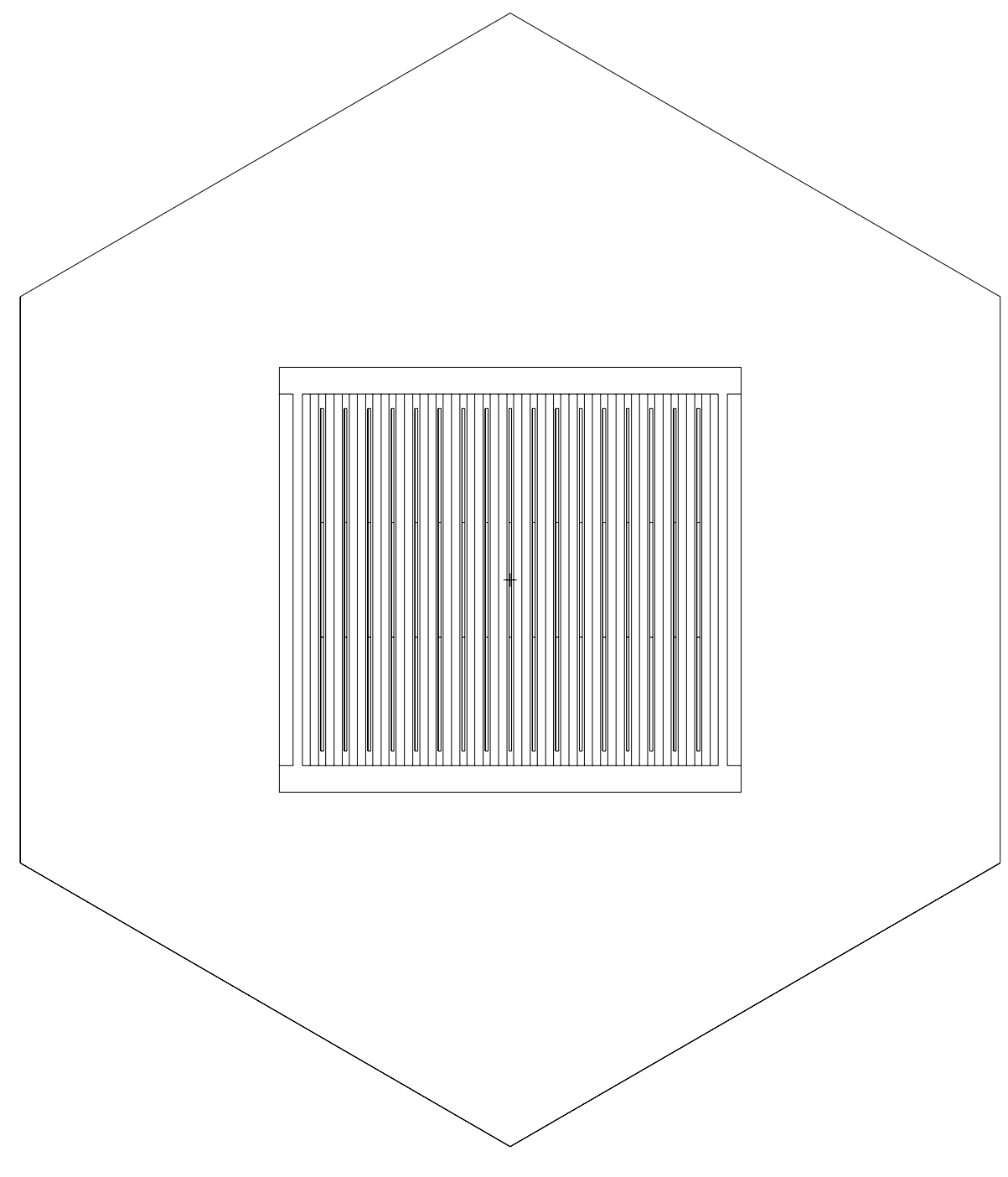

Planar view, $\mathrm{z}=-15 \mathrm{~cm}$

Figure 1 - NBSR single-element model geometry 


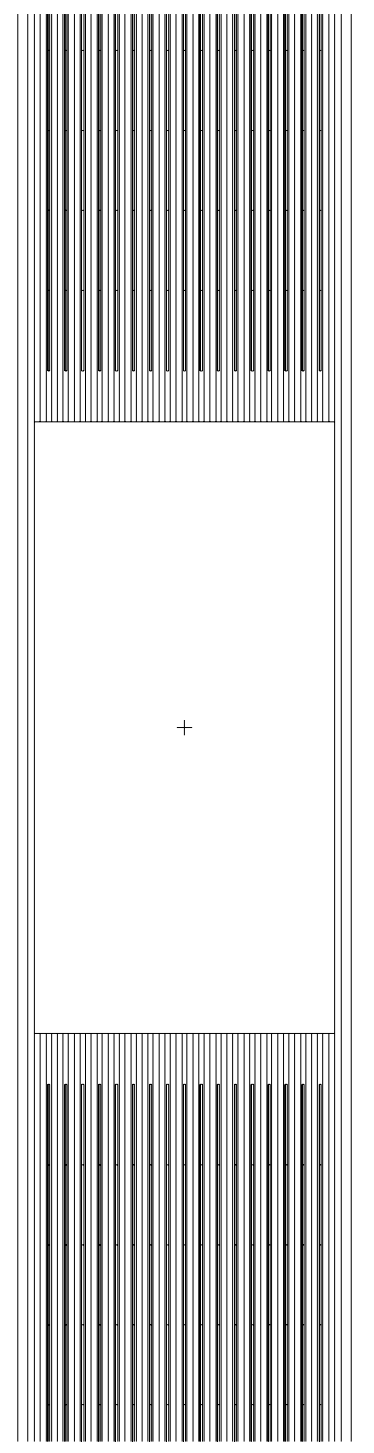

Close-up elevation view showing mid-plane gap and fuel plates

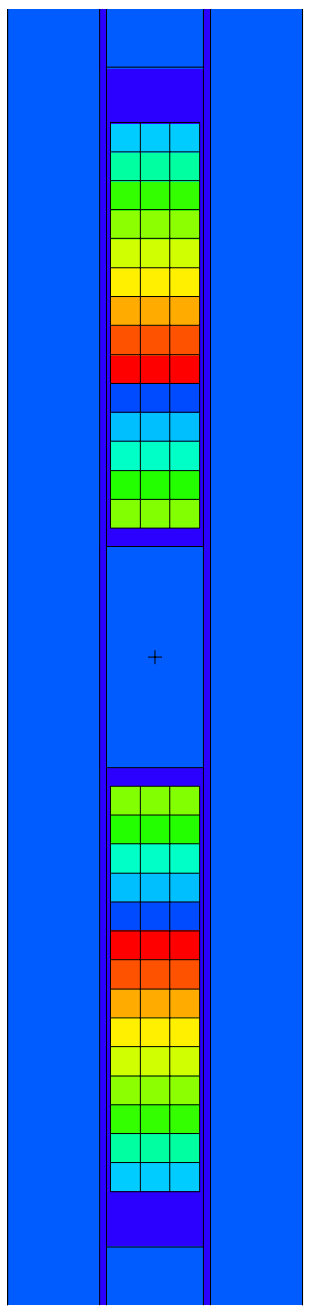

Close-up elevation view showing axial burn-up zones (colors repeated every 10 materials)

Figure 2 - Elevation views of the mid-plane gap and the burn-up zones in the axial burn-up model 


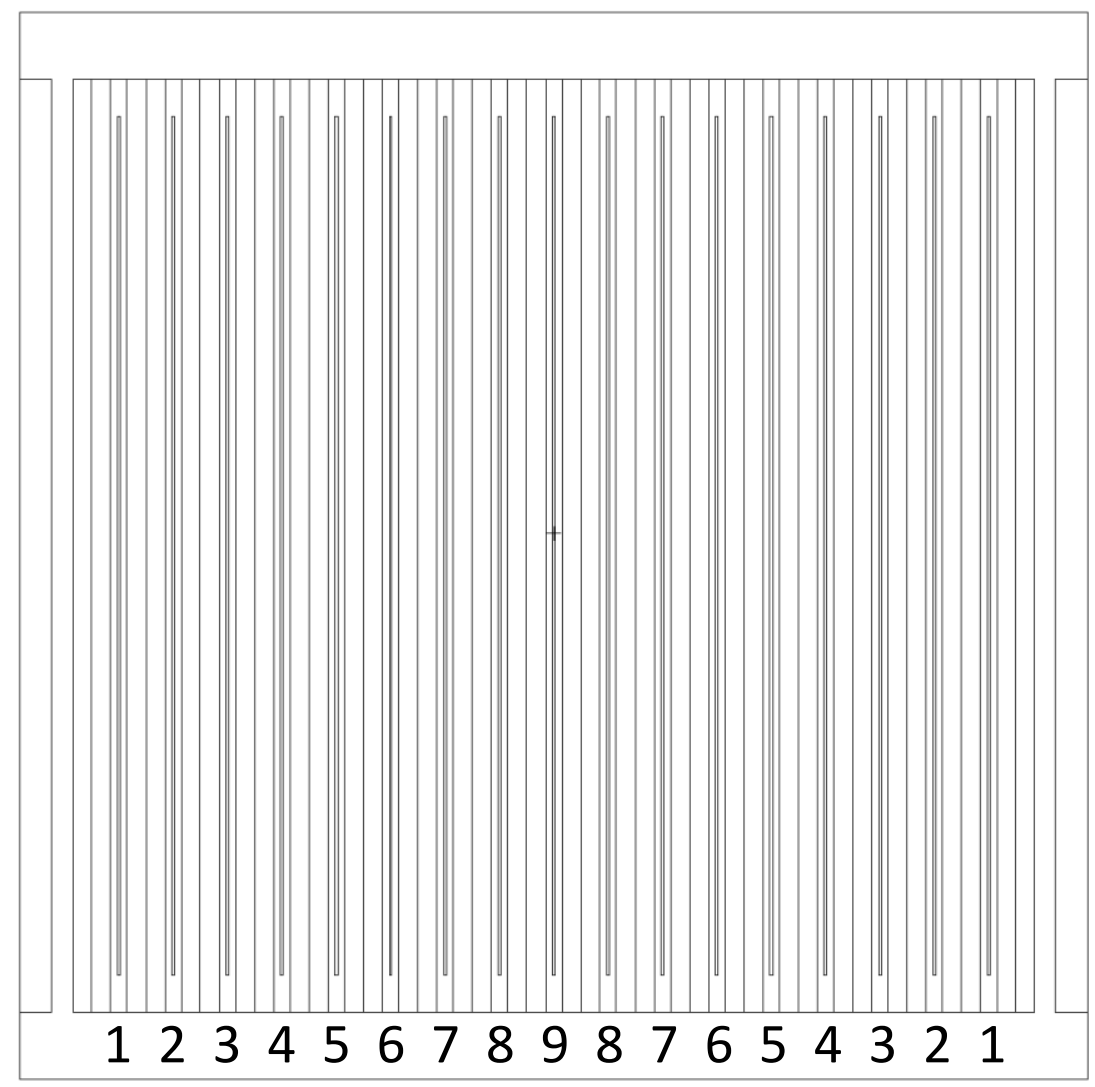

Figure 3 - Definition of the plate numbering scheme in the plate-wise burn-up model 


\section{Assessment of the Single-Element Model}

The objective of this section is to demonstrate the ability of the single-element model to reproduce significant results from the full-core analysis. The following parameters from the single-element model are compared to results from the full-core NBSR model for both HEU and LEU fuel:

- the neutron energy spectrum in the mid-plane gap,

- the axial fuel element power distribution for a fresh element,

- the plate-to-plate power distribution for a fresh element,

- and the fuel inventories as a function of element burn-up.

The neutron energy spectrum was tallied in the mid-plane gap between the upper and lower halves of the fuel element. The NBSR is designed so that the thermal flux peaks in the mid-plane gap. This makes the power density highest at the edges of fresh fuel elements near the mid-plane gap and tends to keep the power high at those locations. The neutron energy spectrum in the mid-plane gap was tallied utilizing MCNP5-1.60 for both the full-core and single-element models. The full-core tally was performed at EOC, when the shim arms are withdrawn from the core (there are no shim arms present in the singleelement model). The neutron energy spectrum is shown in Figure 4 for the relevant energy range. This result demonstrates that the single-element models accurately reproduce the neutron energy spectrum in this region of high importance. It also incidentally shows that there is little difference in the spectrum for the HEU and LEU cores.

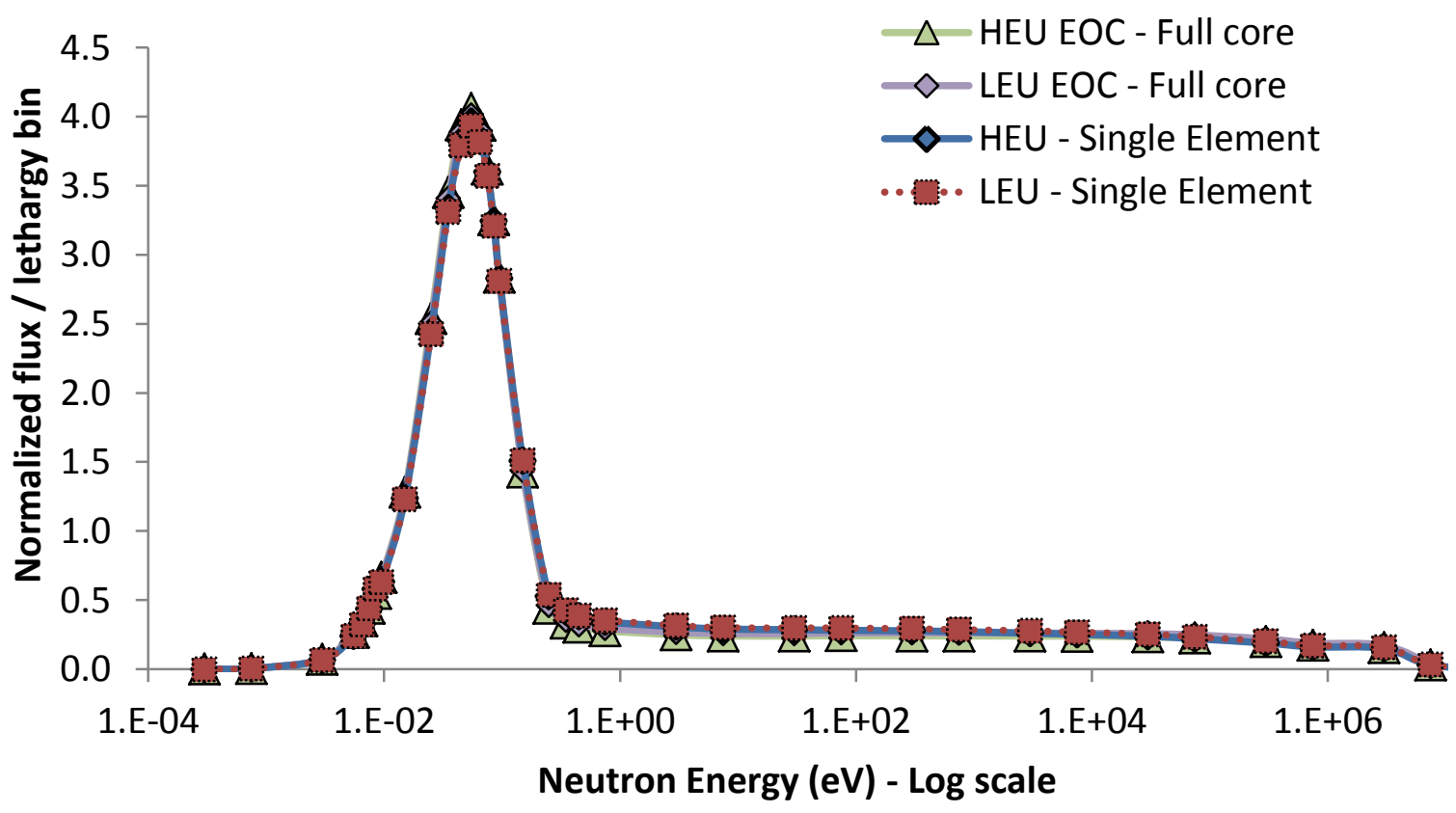

Figure 4 - Neutron energy spectrum in the mid-plane gap 
The axial power distributions in the single-element model were compared to the axial power distributions from the A-4 element of the NBSR full-core model, for both HEU and LEU fuel. The A-4 element is a fresh fuel element. The comparison is shown for HEU in Figure 5 and for LEU in Figure 6. Overall, the single-element (SE) model reproduces the power distributions in element A-4 reasonably well.

One of the key limitations of the single-element model is demonstrated by this comparison. The singleelement model lacks the shim arms. Thus, the axial relative power is under-predicted for the lower half of the fuel element and over-predicted for the upper-half of the fuel element. In the full-core model the axial power shape at SU is depressed in the upper half of the fuel due to the shim arms. At EOC, when the shim arms are withdrawn from the NBSR, the axial power profiles are quite similar. It is evident that a single-element burn-up study, when applied to Cycle 1 of the A-4 element, would be conservative for the lower half of the assembly but non-conservative for the upper half of the assembly.

The fuel element average plate power is compared in Figure 7 for element A-4 and the single-element model. The plate-to-plate power is similar for both cases. The key difference is that the plate-to-plate power has a slight bias towards the center of the NBSR core in the A-4 result. In Figure 7, the center of the core is closest to plate 17. Due to the symmetry of the geometry, the single-element axial and plateto-plate power distributions are symmetric. This comparison demonstrates another key limitation of the single-element model, namely the radial boundary condition that neglects the impact of the core geometry and radial neutron leakage. However, the single-element model is useful for quantification of impact of isolated geometric features on the fuel element burn-up distribution.

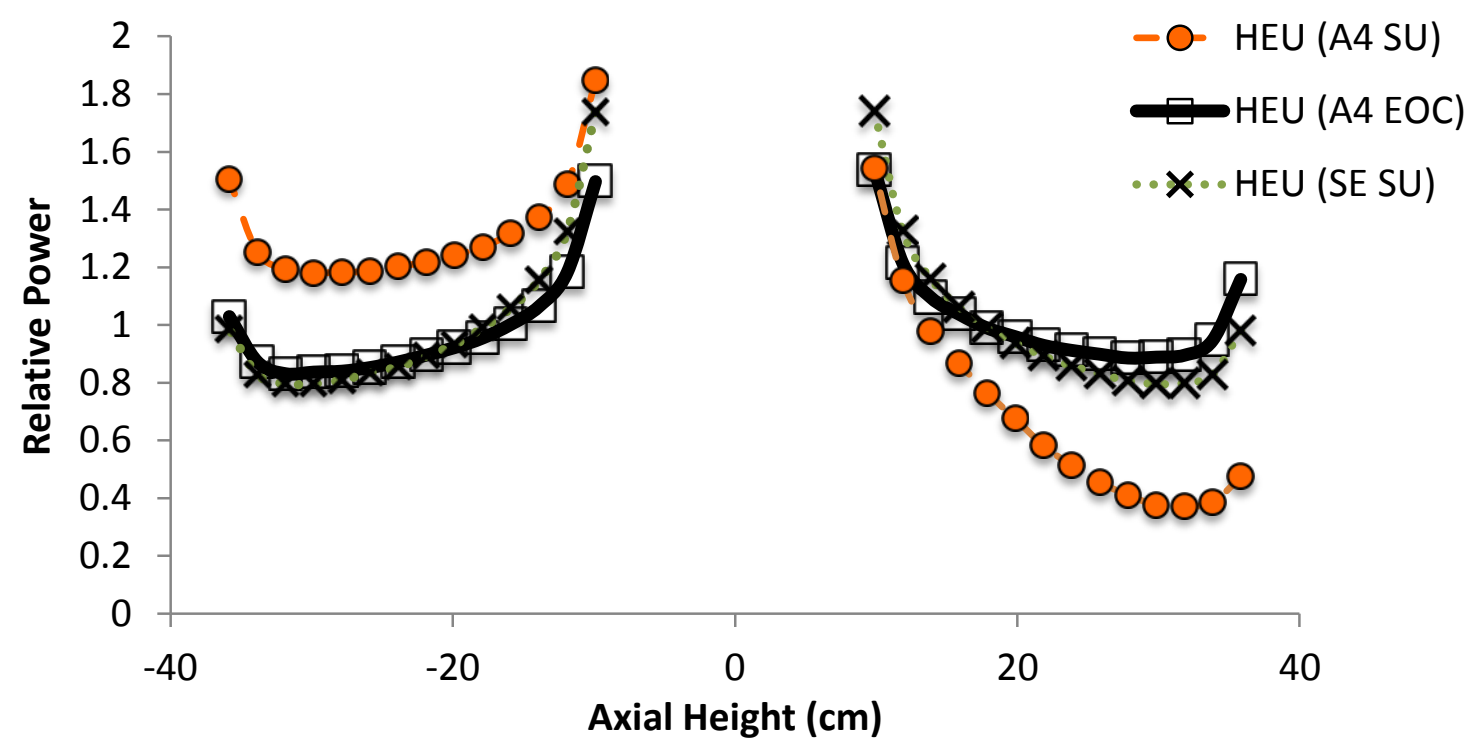

Figure 5 - Axial power distributions in the HEU NBSR (element A-4) vs. the single-element model 


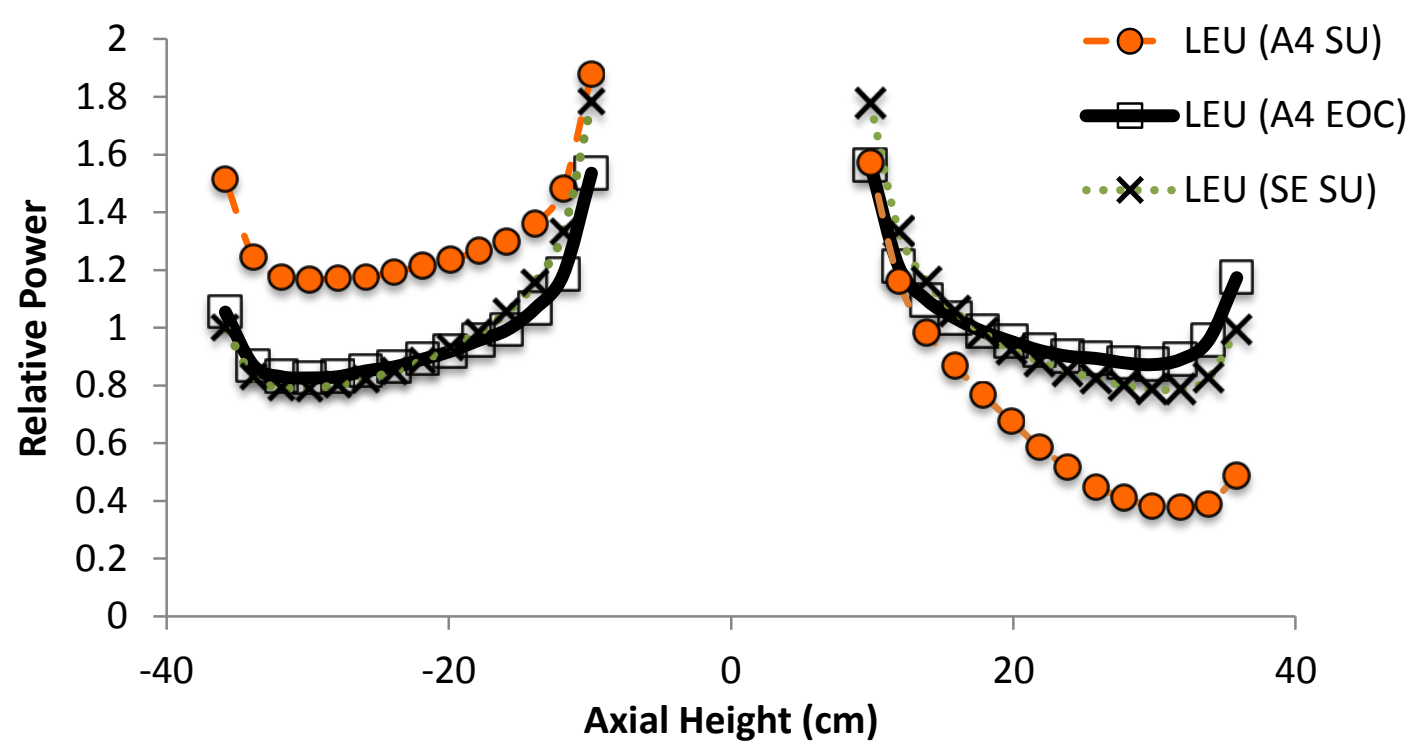

Figure 6 - Axial power distributions in the LEU NBSR (element A-4) vs. the single-element model

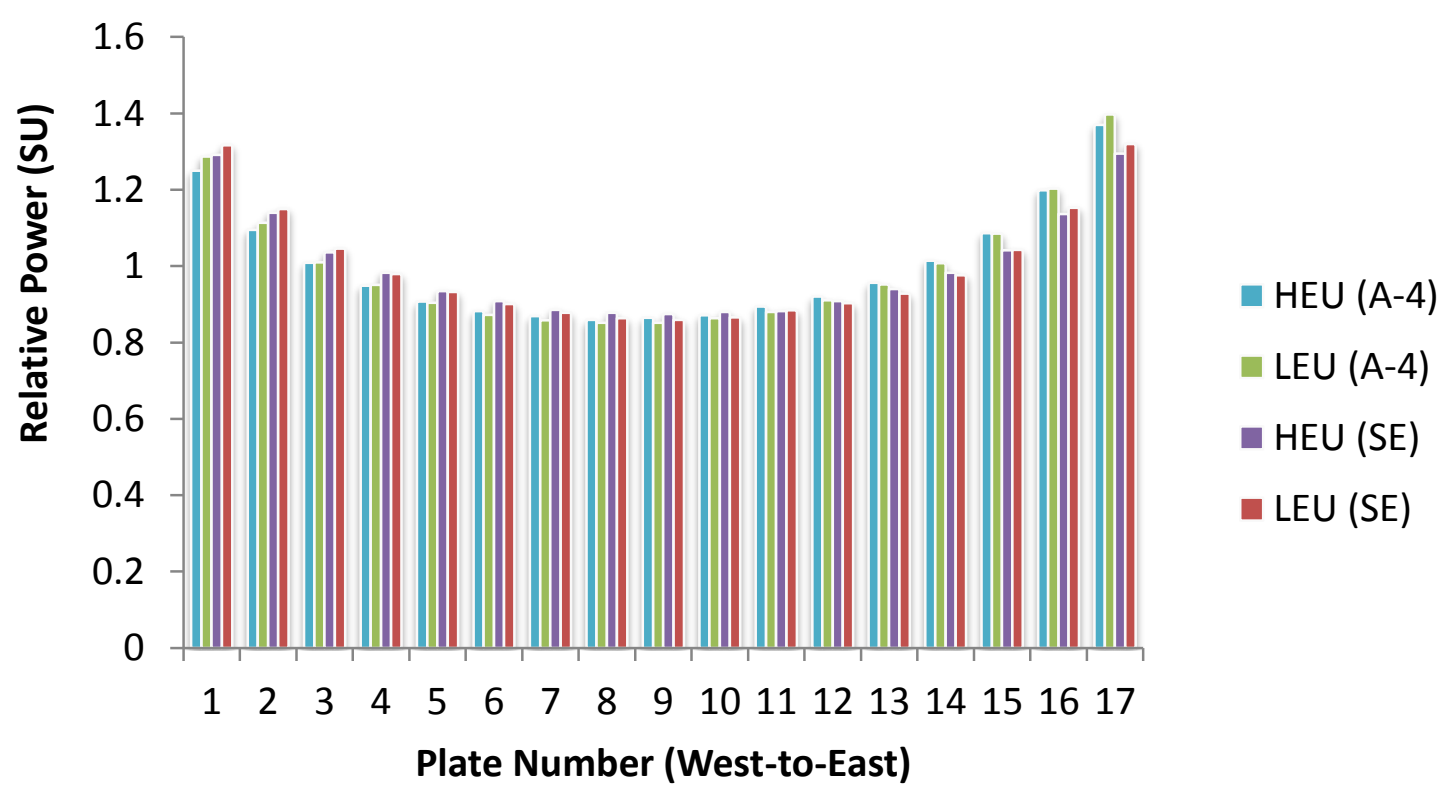

Figure 7 - Plate-to-plate power in the NBSR (element A-4 at SU) vs. the single-element model

The single-element model was utilized to study the effect of axial burn-up on the power distribution in the NBSR. MCNPX was utilized as the tool for the burn-up analysis. The CINDER' 90 depletion analysis code is integrated into MCNPX. Twenty-four burn-up steps were utilized in a predictor-corrector calculation. The calculation sequence consisted of a predictor calculation for 19.25 full power days, a corrector calculation for 19.25 full power days, and a decay calculation for 10.5 days. The fission power of the single-element was assumed to be $0.6667 \mathrm{MW}_{\text {th }}$ (average element power) in each cycle. The statistical relative error of the local fission reaction rates and neutron fluxes was less than 0.003 for all of the calculations described in this document. 
The integral inventories in the single-element were compared to the integral inventories in each element within the full-core burn-up calculation. It should be noted that some of the NBSR elements are in the core for seven cycles and the other NBSR elements are in the core for eight cycles. The HEU U-235 mass is shown in Figure 8 as a function of cycle and position in the NBSR core. The 7E, 7W, 8E, and $8 \mathrm{~W}$ designators represent fuel elements with different irradiation history due to the fuel-shuffling scheme. Generally, the relative differences in U-235 mass in a given element are within $1 \%$ of the single-element model. The Pu-239 build-up in the HEU NBSR is shown in Figure 9. The corresponding LEU results are shown in Figure 10 - Figure 11. The single-element burn-up results are an excellent approximation to the integral isotopic vectors within the NBSR full core model.

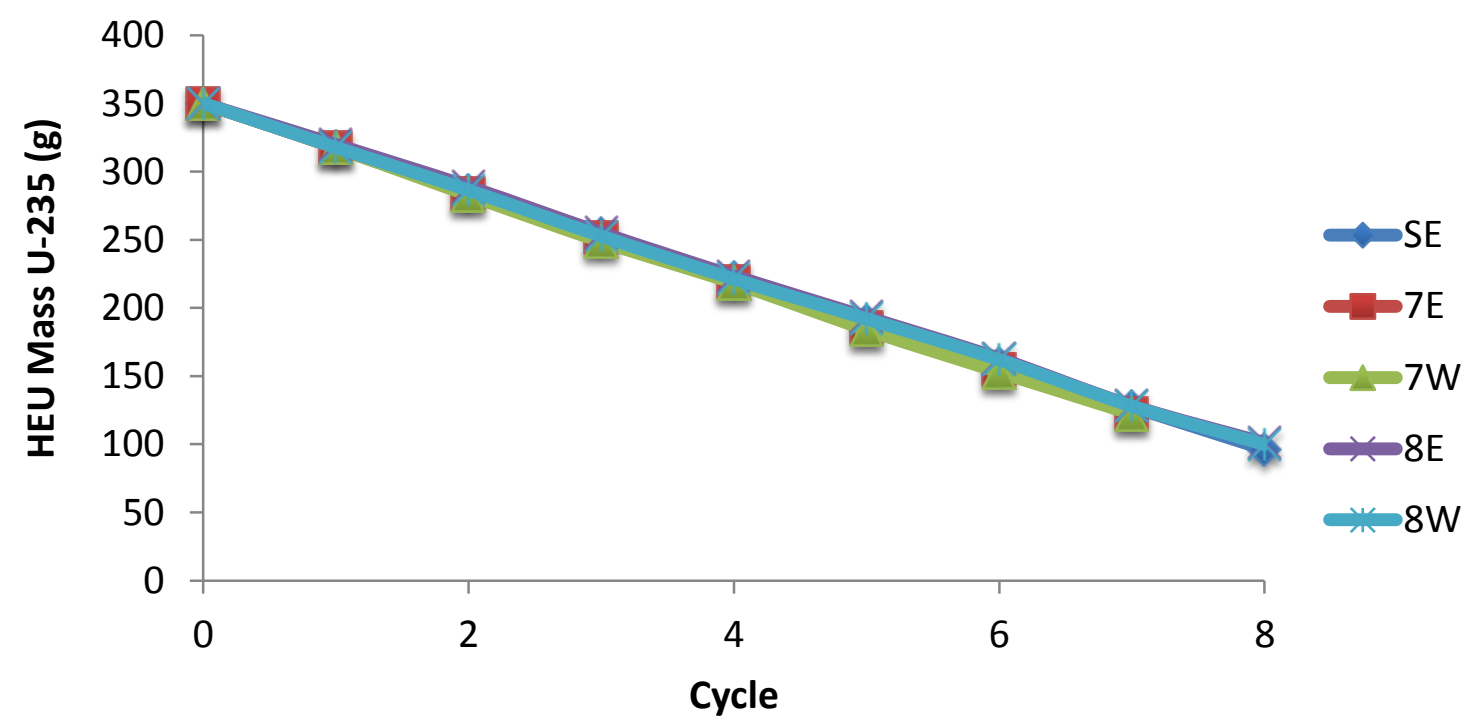

Figure 8 - Mass of U-235 per element as a function of cycle for HEU single-element and NBSR

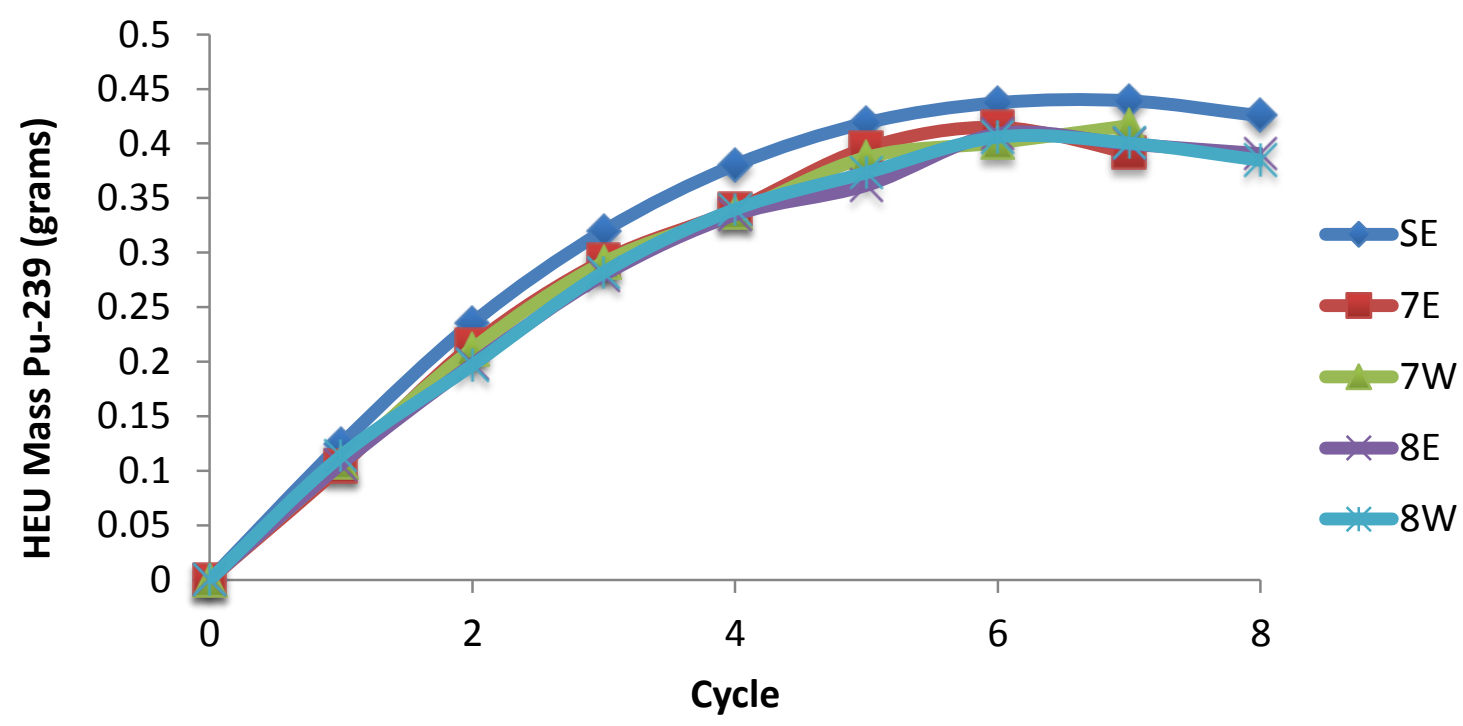

Figure 9 - Mass of Pu-239 per element as a function of cycle for HEU single-element and NBSR 


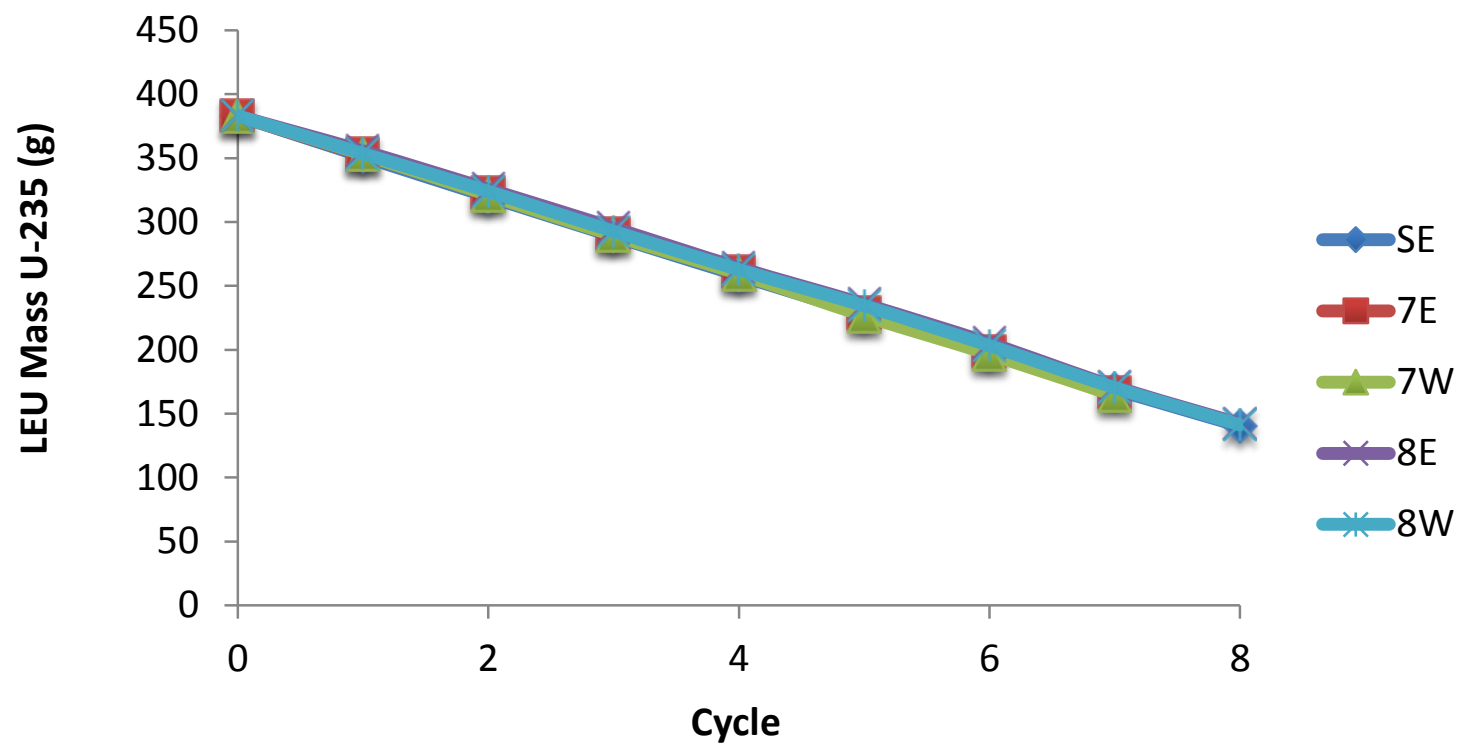

Figure 10 - Mass of U-235 per element as a function of cycle for LEU single-element and NBSR

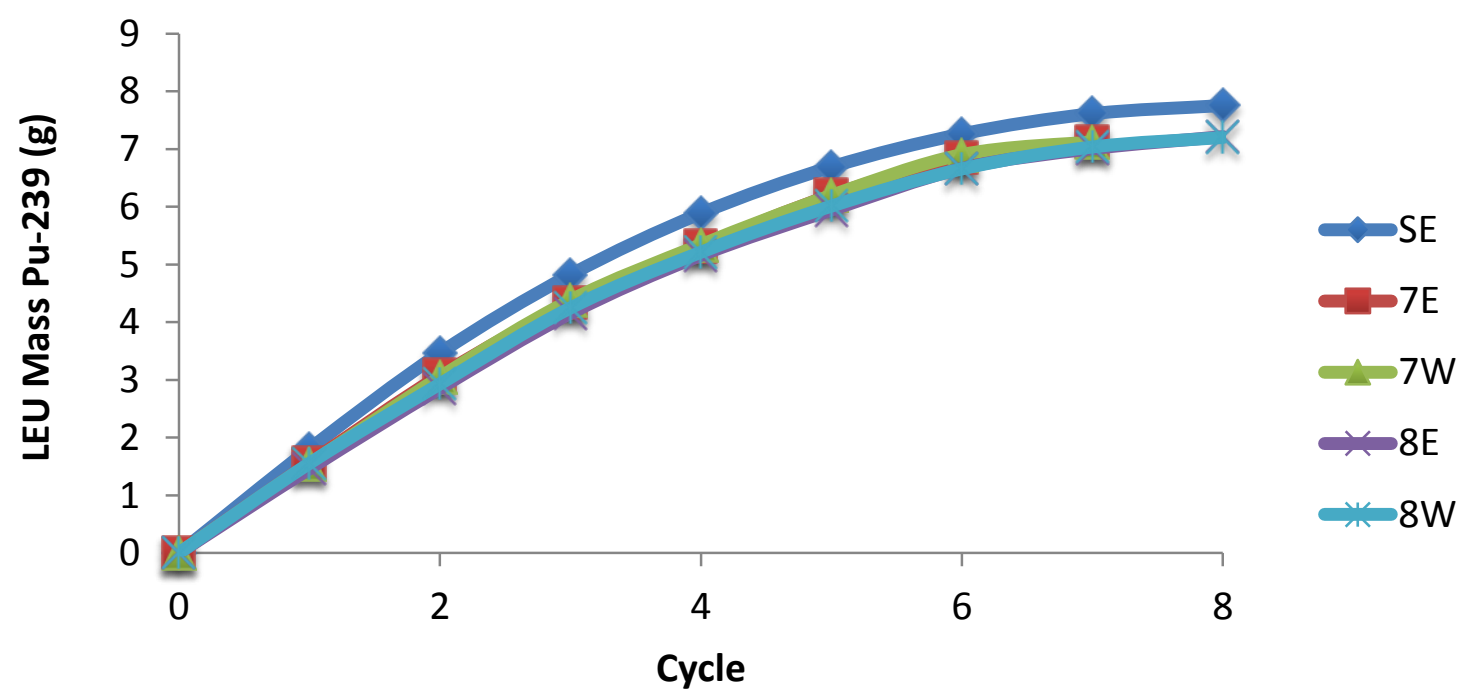

Figure 11 - Mass of Pu-239 per element as a function of cycle for the LEU single-element and NBSR 


\section{Axial Power Distributions as a Function of Burn-Up}

The axial power distributions in the single-element model were extracted as a function of cycle. Because the single-element model geometry is symmetric, and the results are identical within the statistics of the calculation, the results from the upper and lower halves of the single-element were averaged. The calculation was performed for both HEU and LEU fuel with both uniform and axially variant burn-up.

The power distribution was extracted as the number of fissions in each cell, as tallied by MCNPX 2.7.0 assuming all of the fission energy is deposited in the fuel element nodes. In reality, some of the fission energy is deposited within the moderator and core structural materials. Thus, the fission distributions presented here are a conservative analog to the respective power distributions.

The HEU axial power distributions assuming uniform burn-up are shown in Figure 12. These power distribution results are reasonable given the fact that within each burn-up step the fuel composition is smeared throughout the entire element. The peak thermal neutron flux occurs in the mid-plane gap [5]. As expected, the peak fission density in the uniform burn-up calculation always occurs in the axial nodes that are adjacent to the mid-plane gap.

The HEU axial power distributions assuming axially variant burn-up are shown in Figure 13. At SU for Cycle 1 the result for the axial power distribution is identical. For the first six cycles the axial node that is adjacent to the mid-plane gap has the greatest relative power. However, this relative power peaking decreases markedly with each cycle, as the local fissile inventory is depleted. Finally, in Cycle 7 and Cycle 8, the local fissile inventory is so depleted that the peak power shifts to the adjacent nodes. For the HEU NBSR fuel, where there is minimal build-up of fissile nuclides, the local fissile inventory, and hence the local fission rate, is almost entirely dependent on the local depletion rate. The error in the uniform burn-up result propagates as a function of cycle and also axial node, as shown in Figure 14. At SU of Cycle 8 the local power distribution differs by as much 50\% when comparing the axially variant and uniform burn-up solutions.

In Figure 15 the HEU cumulative burn-up is shown for each node at EOC. The HEU axial power fraction at EOC is shown in Figure 16. By the end of Cycle 8, the fissile inventory is almost totally depleted within the axial node adjacent to the mid-plane gap. Thus, in Cycle 8 for the HEU element, the uniform burn-up fission distribution will predict a hot spot in an axial location where the local relative power is actually $20 \%$ lower than the average. A plot of the cumulative depletion rate divided by the power fraction is shown as a function of cycle in Figure 17. This plot is useful in understanding the extreme changes in relative power that occur in the node adjacent to the mid-plane gap. The slope of this curve illustrates the relative "acceleration" of the depletion rate in the node near the mid-plane gap. Relative to the average node, the node adjacent to the mid-plane gap is severely "over-burned." This analysis shows that most of the axial nodes can be lumped together and modeled reliably. However, the axial nodes closest to the mid-plane gap have a significantly different depletion rate and therefore the power peaking is over-predicted when lumped with the other nodes.

Some of the differences between the uniform burn-up and the axial burn-up models can be explained by considering the axial flux distributions. Due to the moderator within the mid-plane gap, the axial location 
of the thermal flux peak stays constant as a function of burn-up, for both the uniform burn-up and the axially variant burn-up cases. The thermal flux, with a group boundary of $0.625 \mathrm{eV}$, is shown in Figure 18. The fixed axial location of the thermal flux peak increases the relative burn-up rate of the nodes adjacent to the mid-plane gap. The fast flux distribution is considerably different for the uniform burn-up and the axial burn-up case, as shown in Figure 19. In the uniform burn-up case the fast flux distribution is nearly constant, but in the axial burn-up case the fast flux distribution shifts away from the mid-plane gap to the axial center of the element in Cycle 8. This is due to the shift in the power fraction, i.e,. the axial fission source distribution.

The LEU results for power distributions with uniform and axially variant burn-up are shown in Figure 20 - Figure 22 and are similar to the HEU results. However, the initial U-235 loading in each LEU fuelled element is 33 grams greater than in each HEU fuelled element. In addition, an order of magnitude more $\mathrm{Pu}-239$ is bred within the LEU elements than the HEU elements. The node that is adjacent to the midplane gap has more fissile material in Cycle 7 and Cycle 8 for the LEU single-element than the HEU single-element. The resultant axial power distribution for axially variant burn-up is somewhat "flattened" for the LEU single-element in Cycle 7 and Cycle 8. The LEU cumulative burn-up at EOC is shown in Figure 23 for each node. The LEU axial power fraction at EOC is shown in Figure 24. The LEU cumulative burn-up divided by the axial power fraction is shown in Figure 25. The LEU burn-up results are consistent with the HEU results, but the change in power fraction of the node adjacent to the midplane gap is less extreme from Cycle 1 to Cycle 8. The LEU thermal flux distributions are shown in Figure 26 and the fast flux distributions are shown in Figure 27.

The axial burn-up power distribution factors (axial relative powers) are shown in Appendix B for both the HEU and LEU cases. The statistical relative error in the local power fraction and neutron fluxes is less than 0.003 for all cases. 


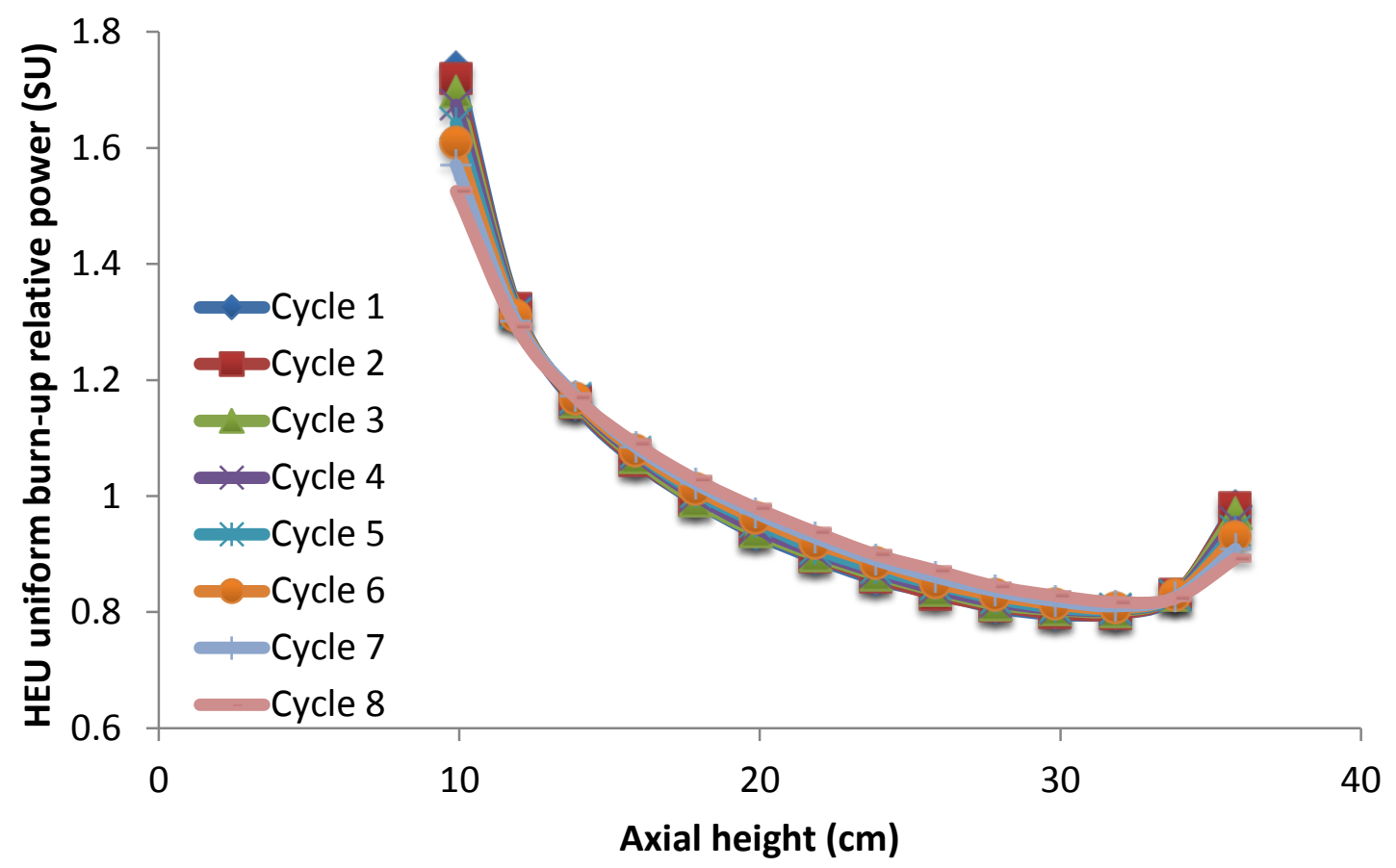

Figure 12 - Single-element HEU axial power distributions assuming uniform burn-up

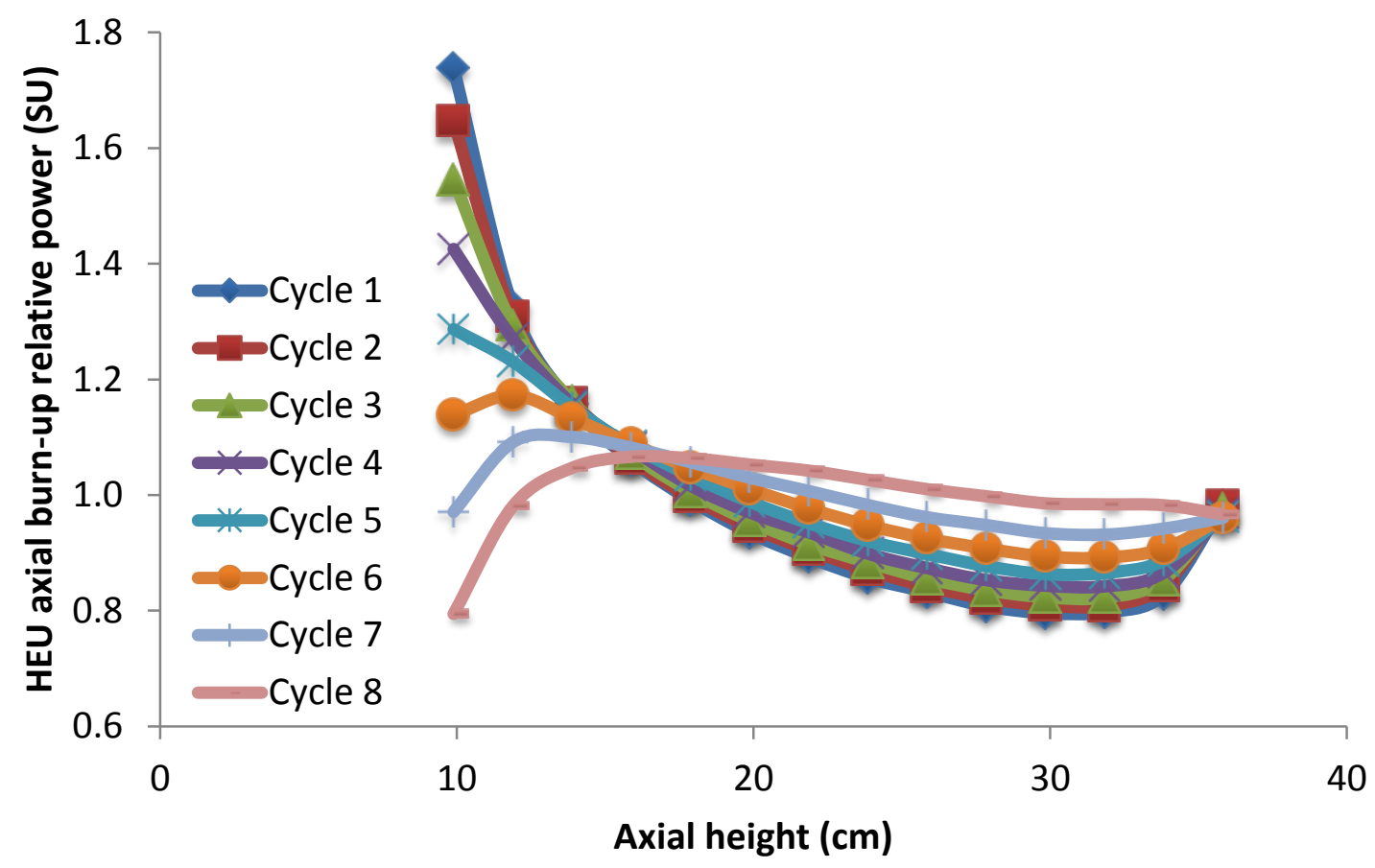

Figure 13 - Single-element HEU axial power distributions assuming axially variant burn-up 


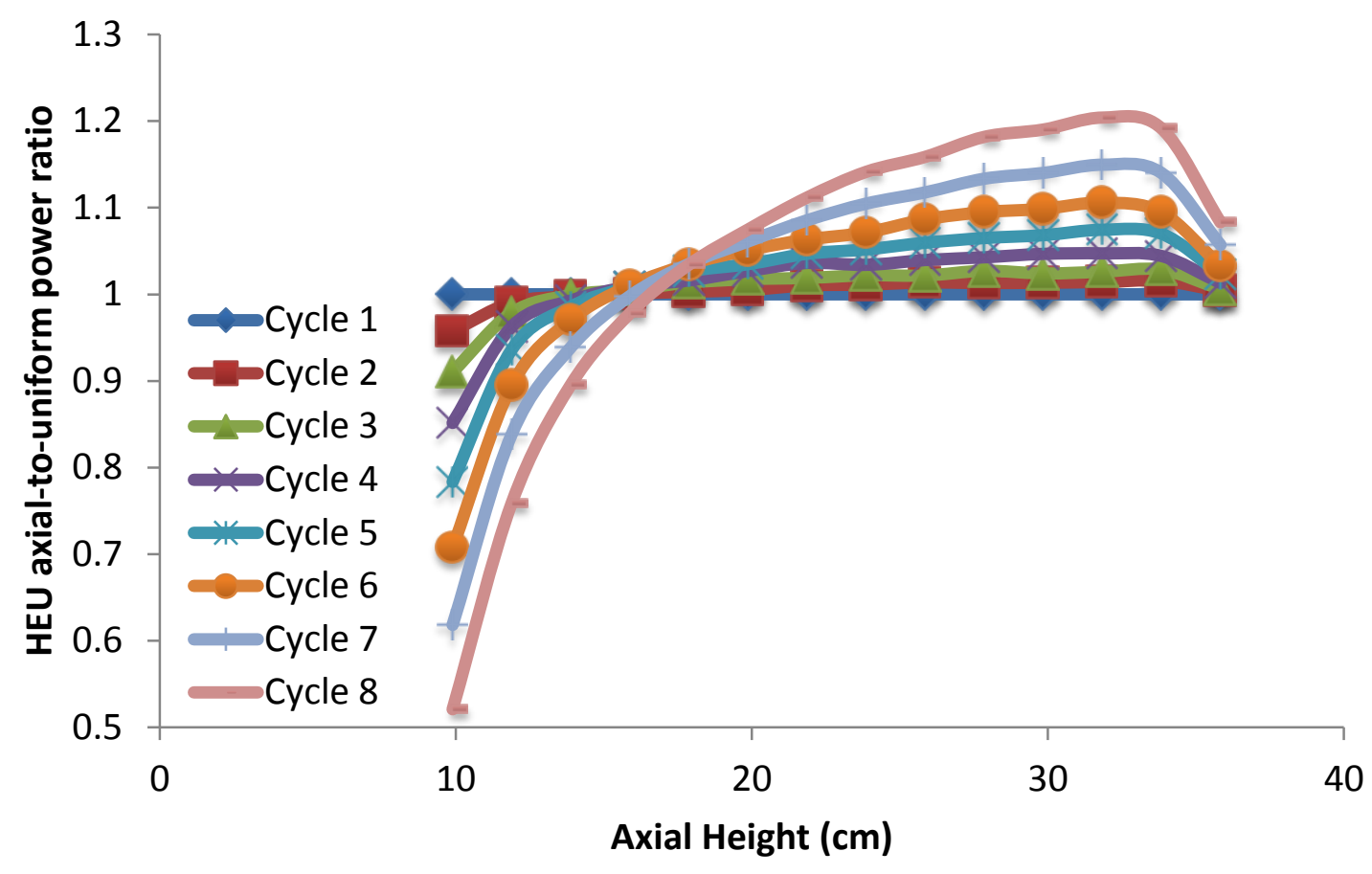

Figure 14 - Single-element HEU axially variant-to-uniform power ratio

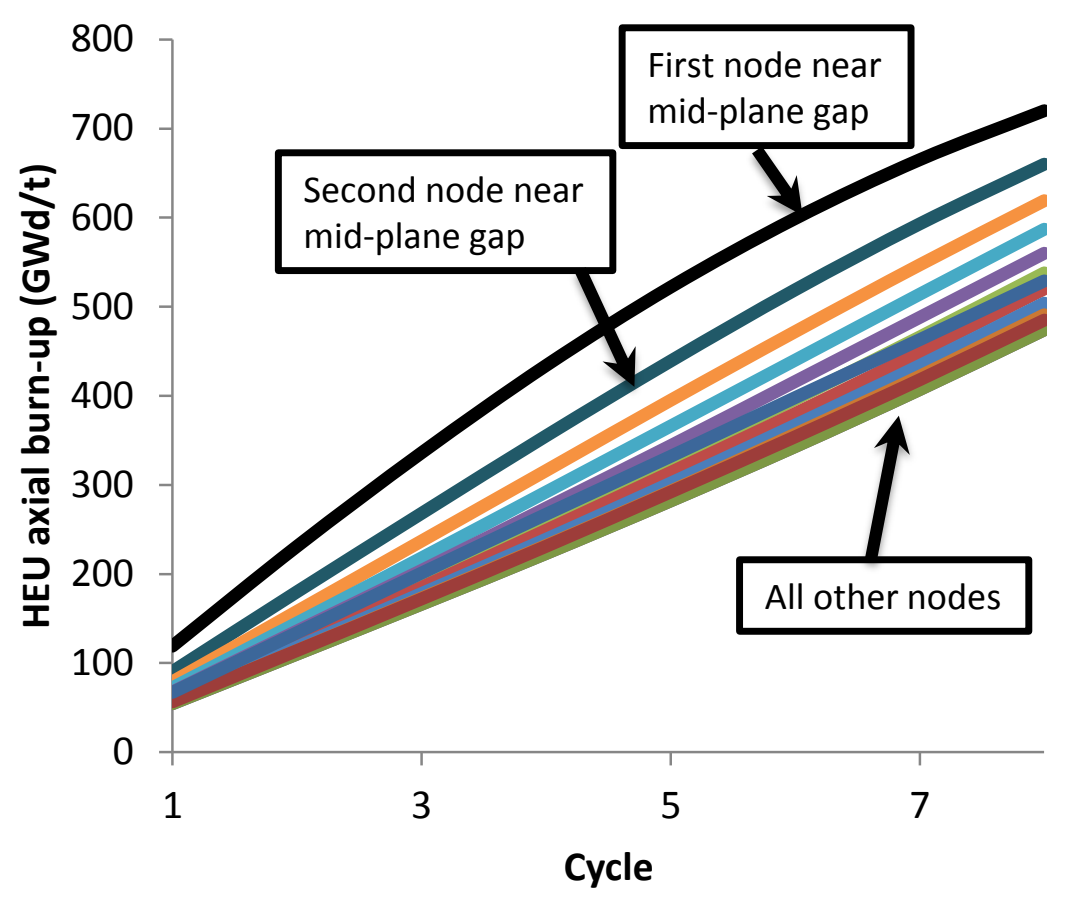

Figure 15 - HEU cumulative burn-up at $\operatorname{EOC}(\mathrm{GWd} / \mathrm{t})$ as a function of cycle 


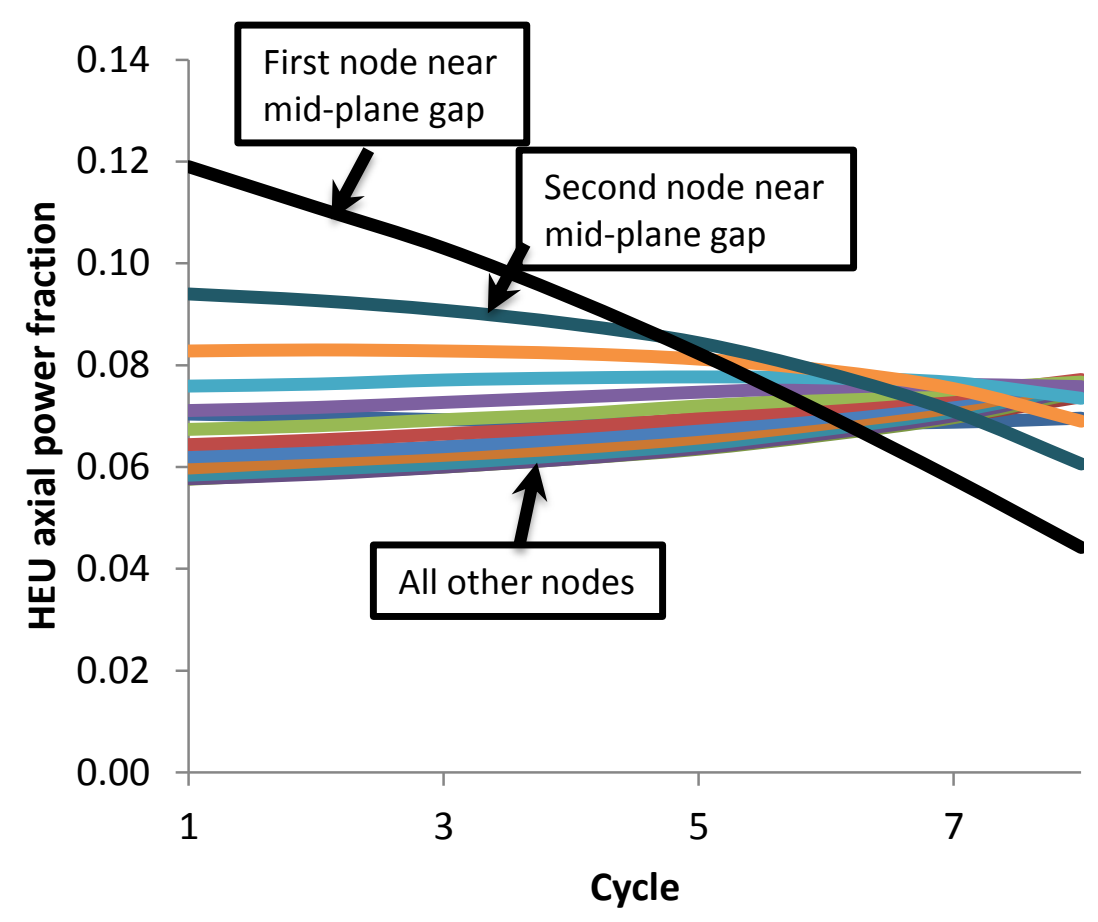

Figure 16 - HEU axial power fraction at EOC as a function of cycle

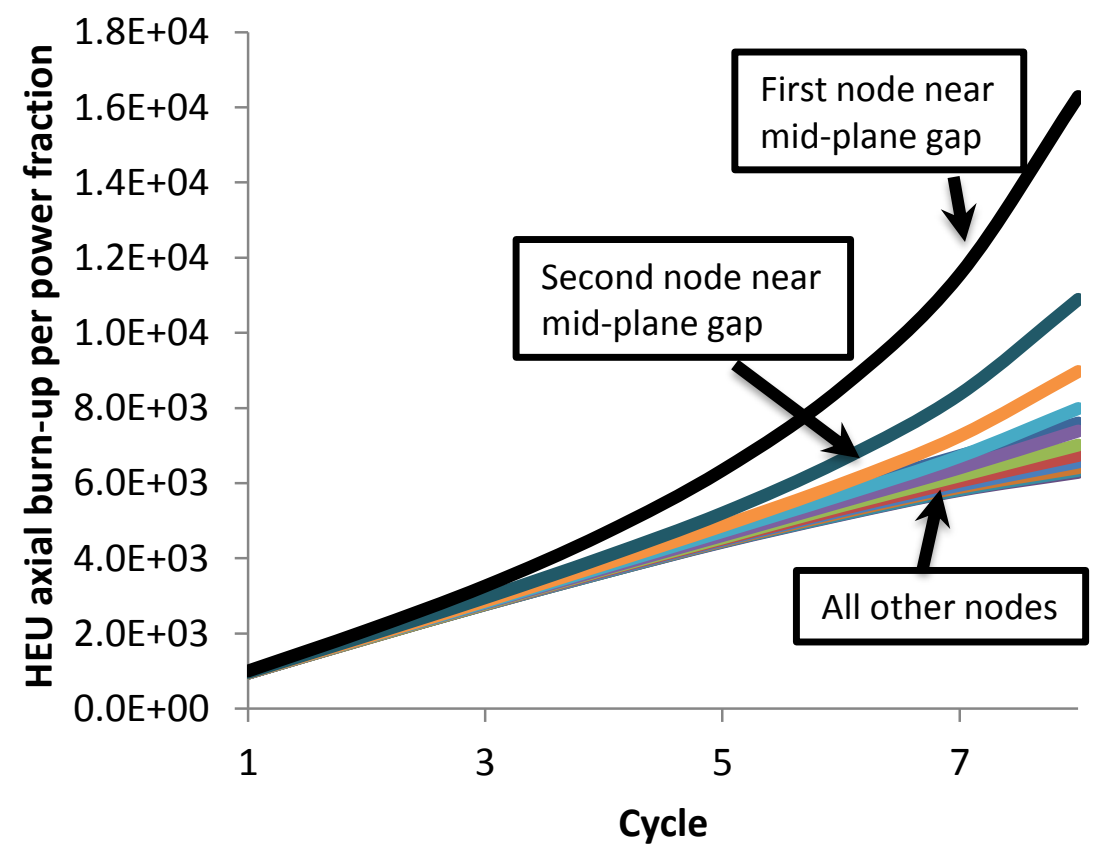

Figure 17 - HEU cumulative burn-up at EOC $(G W d / t)$ per axial power fraction 

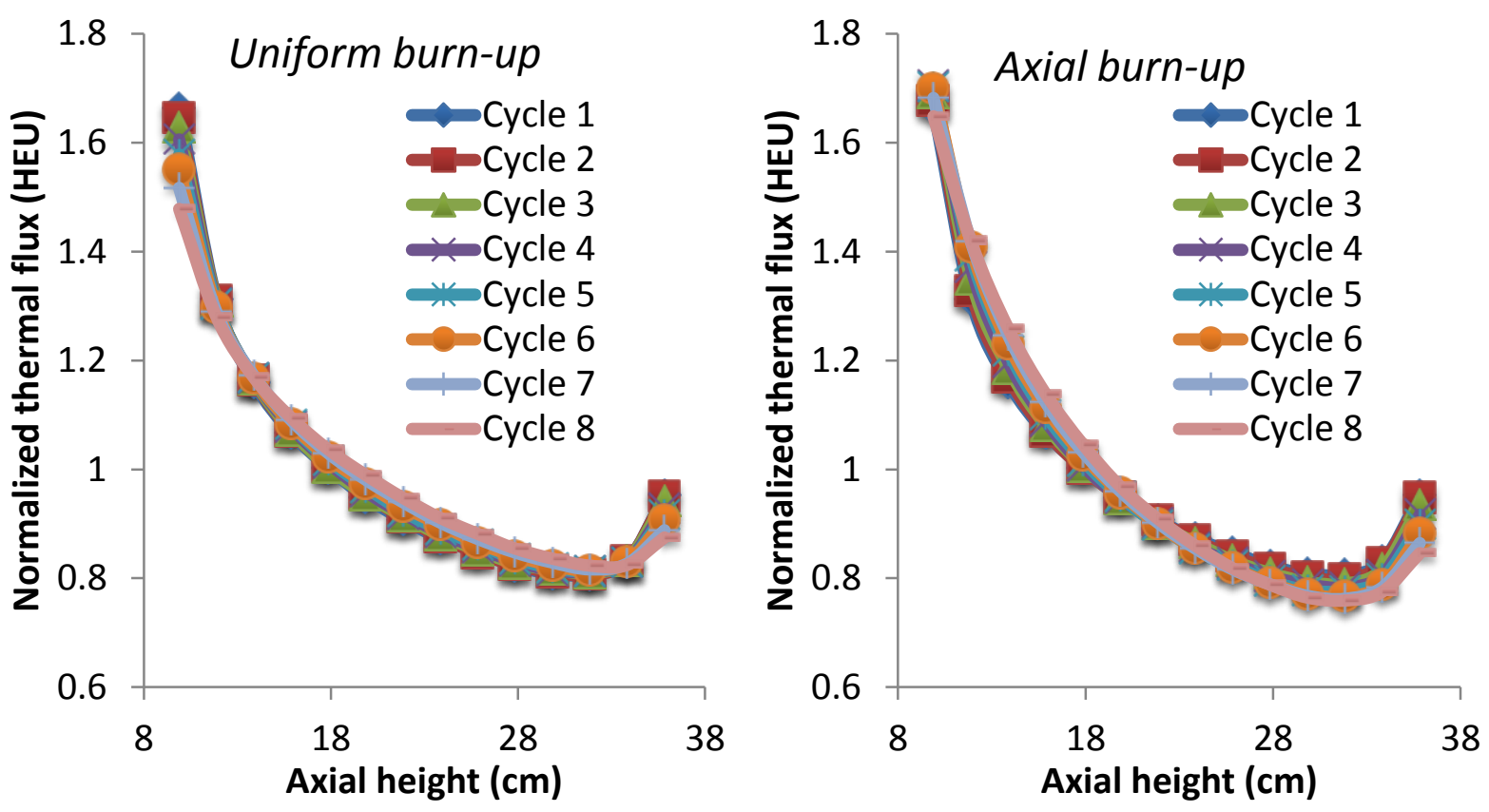

Figure 18 - HEU axial thermal flux distributions
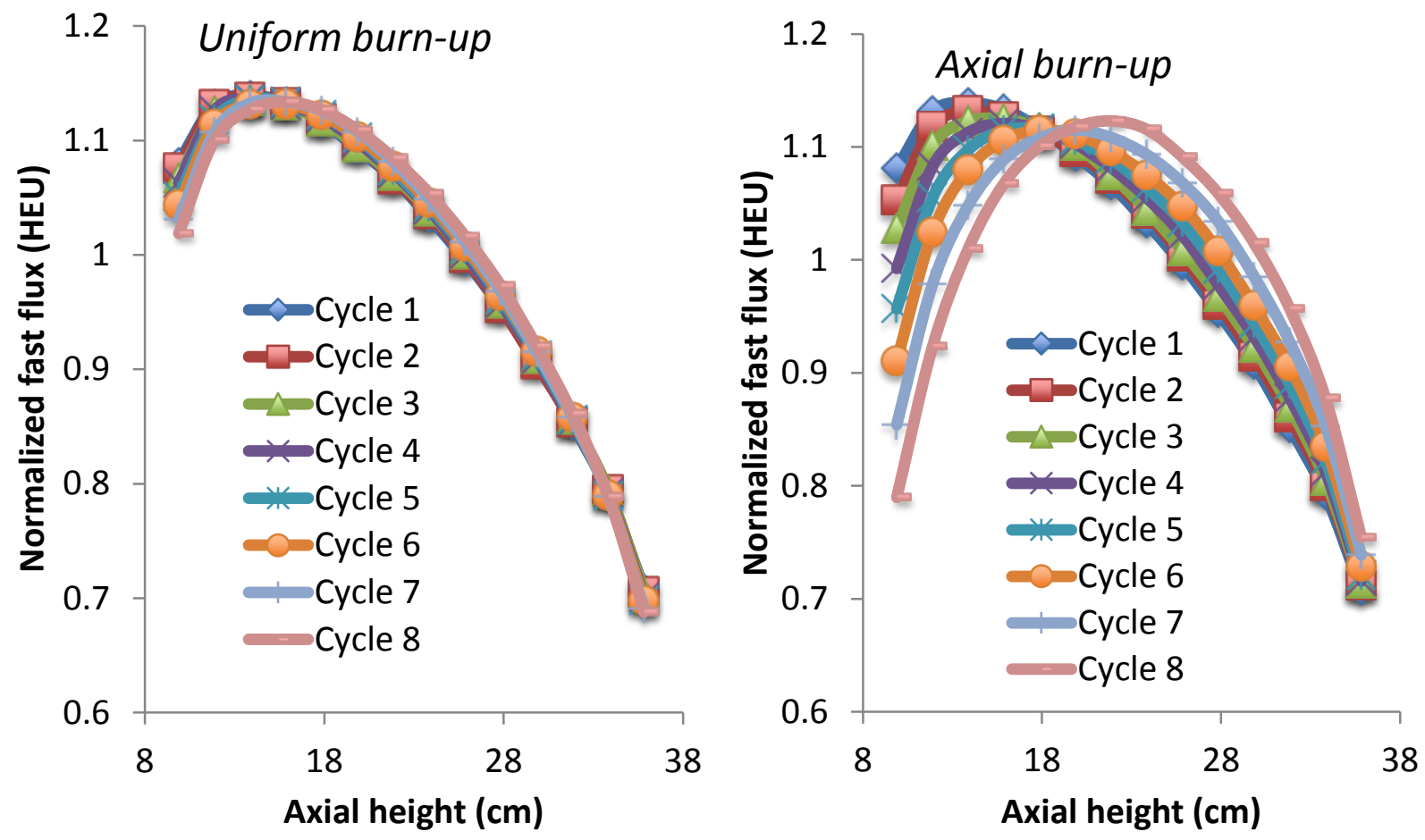

Figure 19 - HEU axial fast flux distributions 


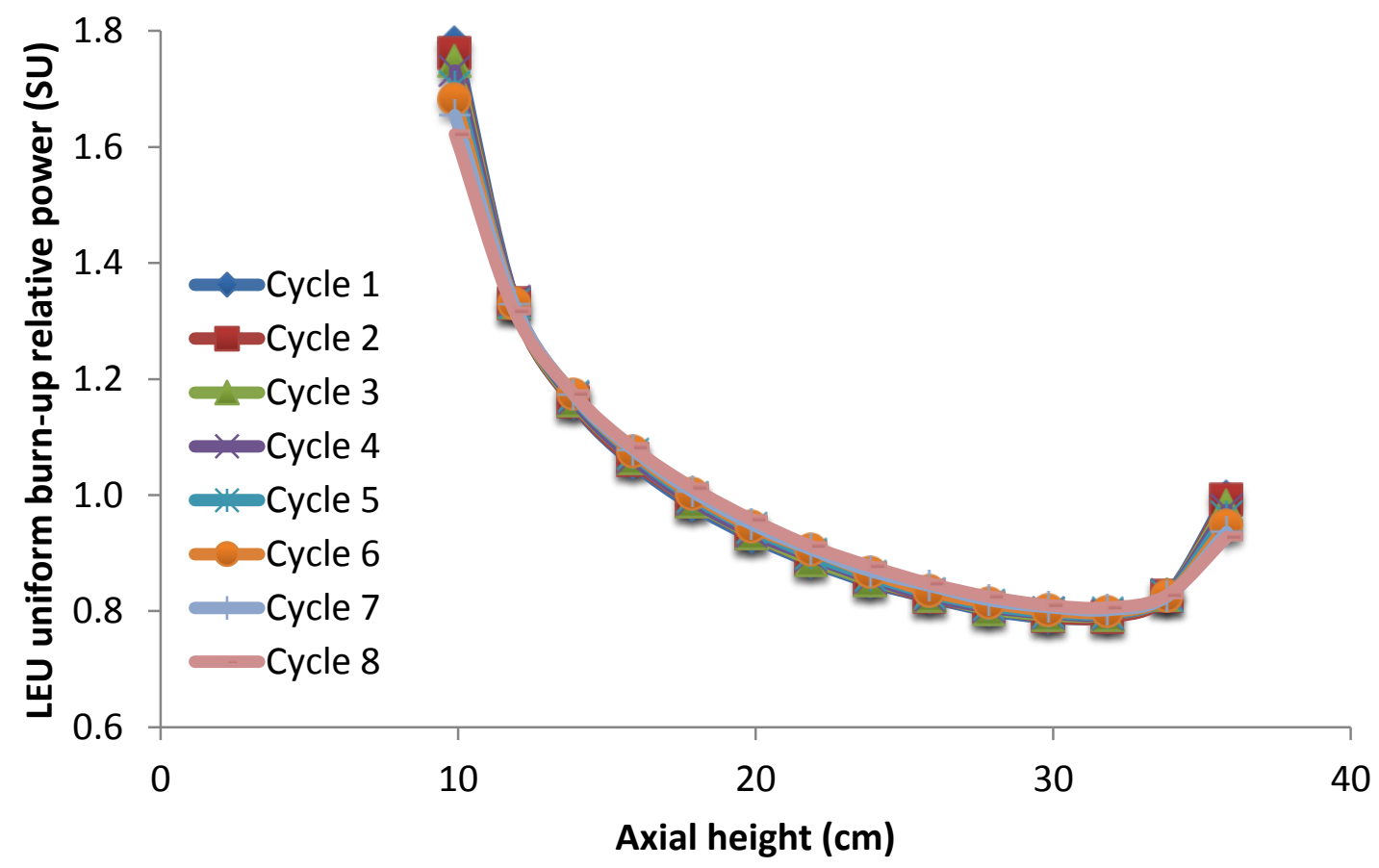

Figure 20 - Single-element LEU axial power distributions assuming uniform burn-up

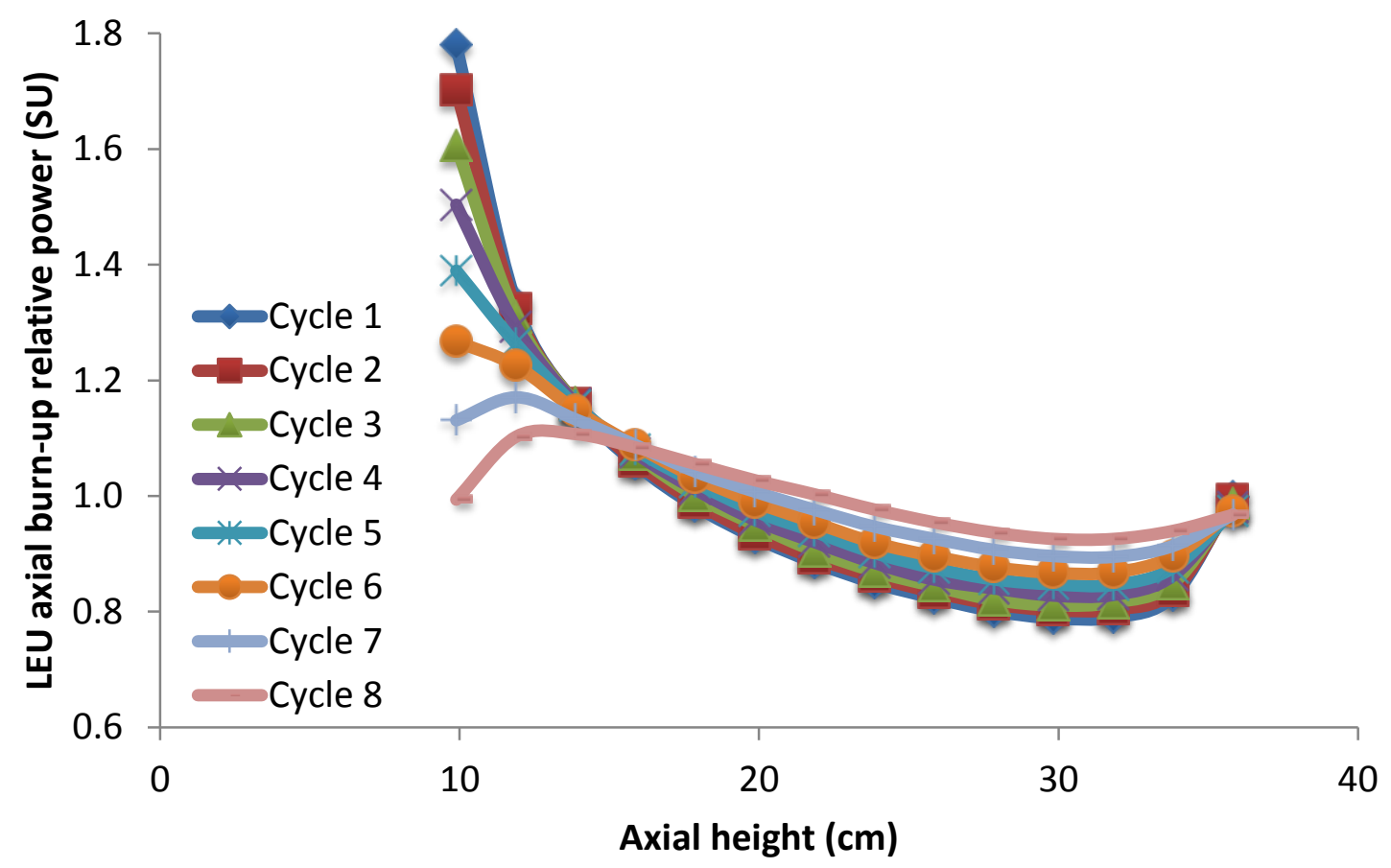

Figure 21 - Single-element LEU axial power distributions assuming axially variant burn-up 


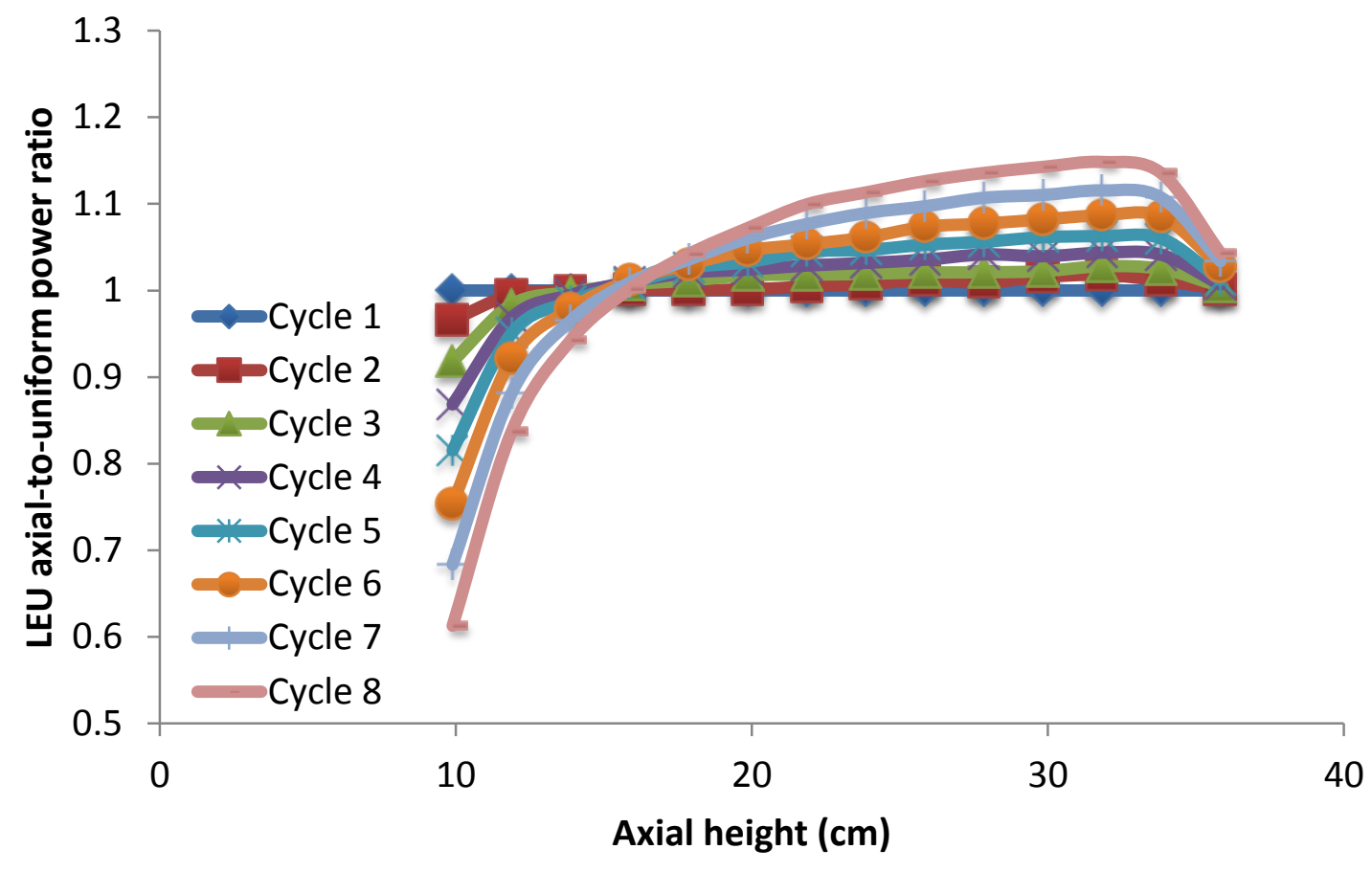

Figure 22 - Single-element LEU axially variant-to-uniform power ratio

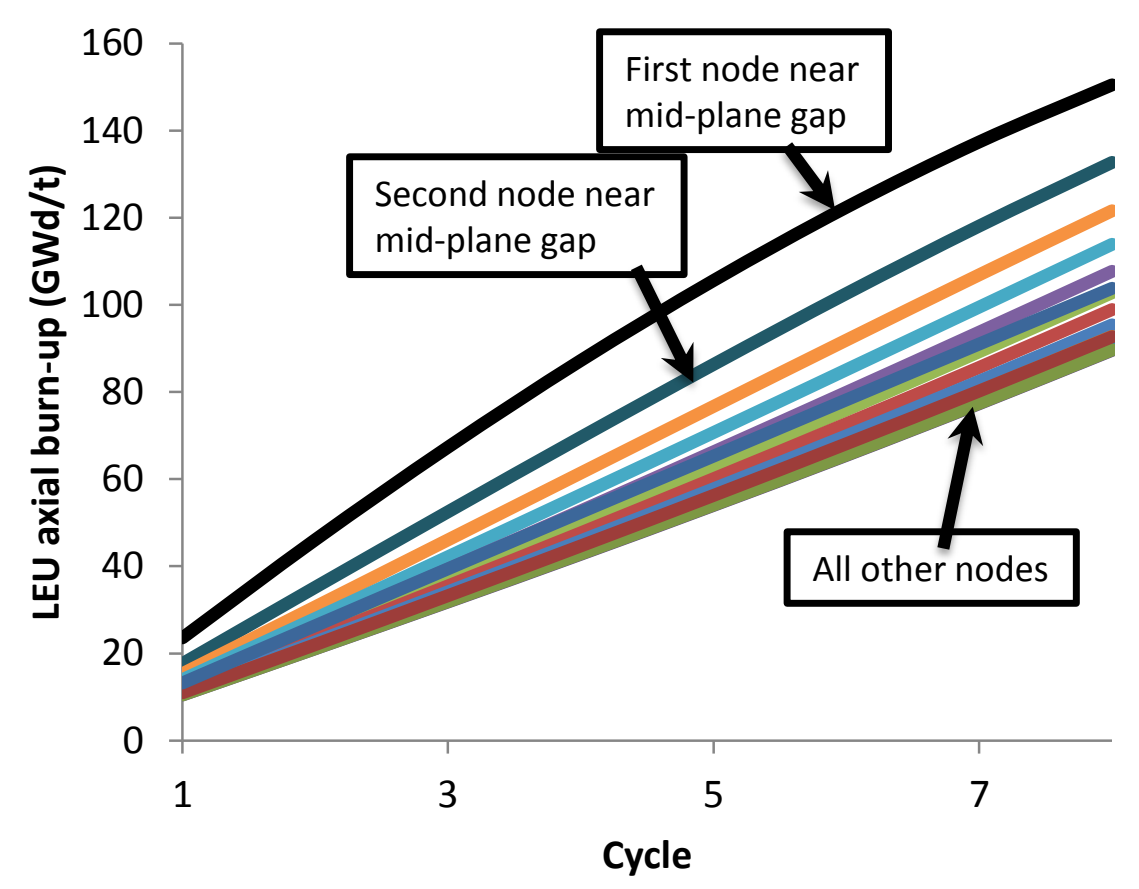

Figure 23 - LEU cumulative burn-up at $\mathrm{EOC}(\mathrm{GWd} / \mathrm{t})$ as a function of cycle 


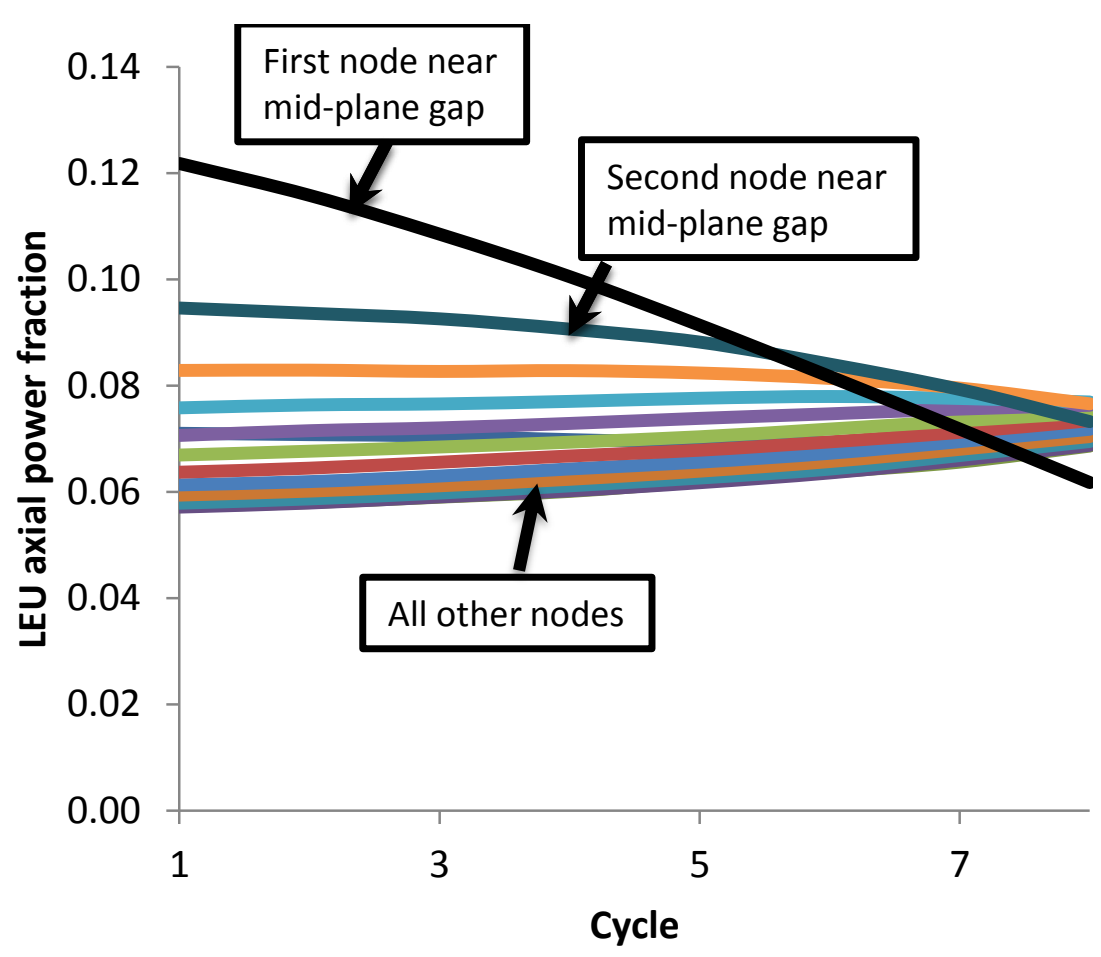

Figure 24 - LEU axial power fraction at EOC as a function of cycle

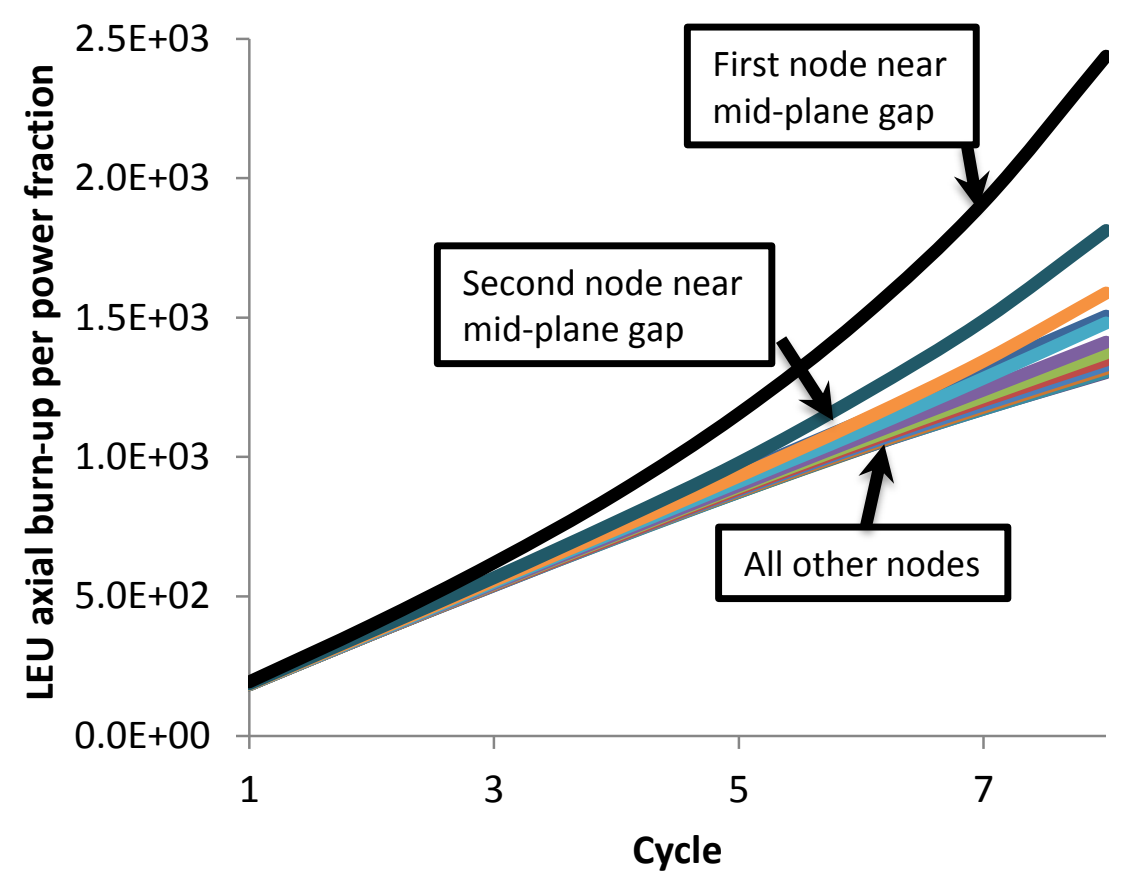

Figure 25 - LEU cumulative burn-up at EOC (GWd/t) per axial power fraction 

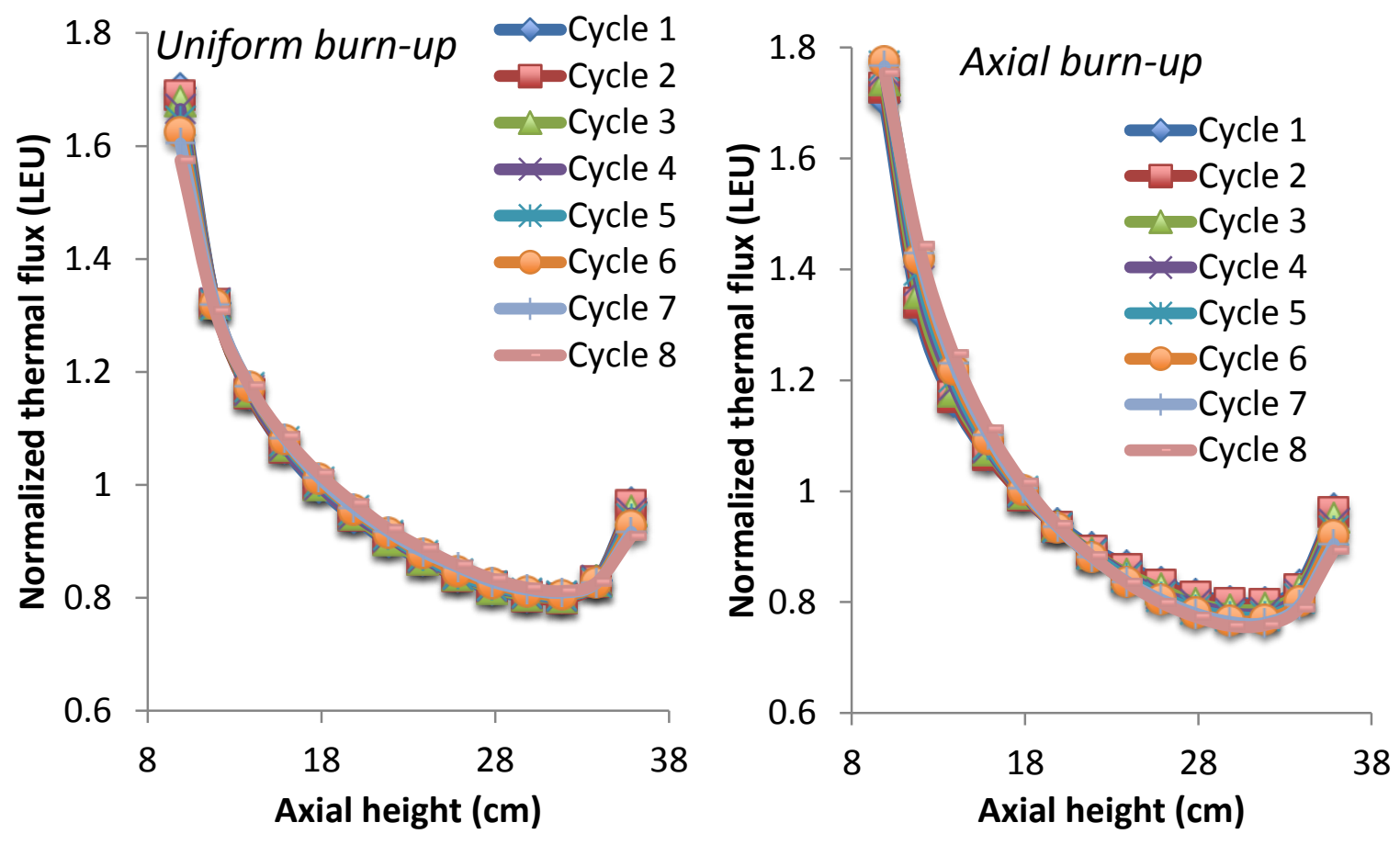

Figure 26 - LEU axial thermal flux distributions
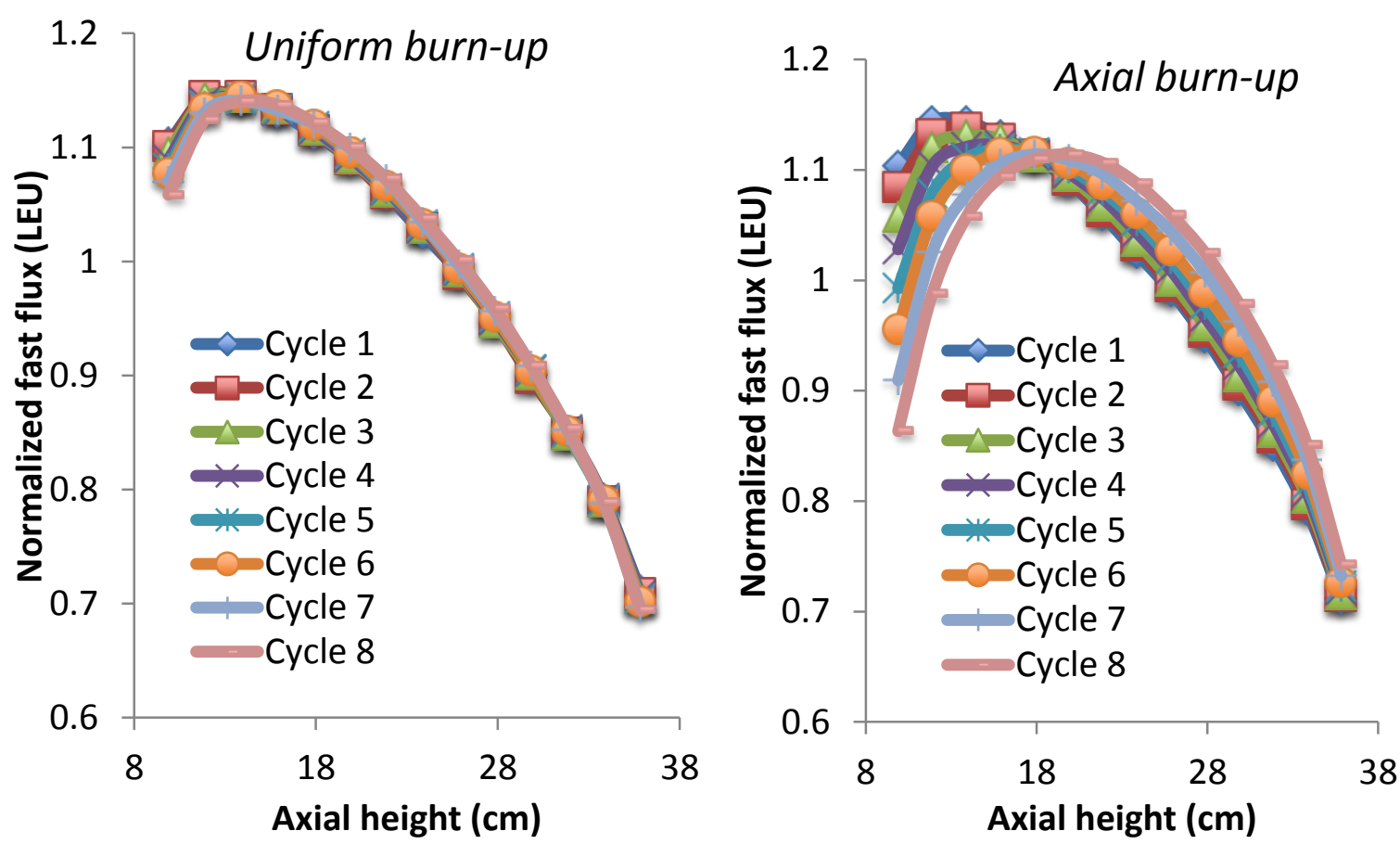

Figure 27 - LEU axial fast flux distributions 


\section{Plate-Wise Power Distributions as a Function of Burn-Up}

The plate-wise and axial power distributions as a function of burn-up were studied separately, to isolate the two effects. The plate-wise burn-up is conceptually similar to the axial burn-up due to similar phenomena; the thermal flux peaks on the exterior edges of the fuel element and the outer plates tend to shield the inner plates from this thermal flux.

The HEU plate power distribution is shown for uniform burn-up in Figure 28 and for plate-wise burn-up in Figure 29. It is notable that the plate-wise power distribution is not constant for the uniform burn-up case. Even with uniform burn-up, the reduction in fissile inventory decreases the self-shielding effect and causes modest reduction in the power of the outer plates. The ratio of the plate power calculated with uniform burn-up to the plate power calculated with plate-wise burn-up is shown in Figure 30. The differences in plate power distribution due to the plate-wise burn-up are significant. When the plate-wise burn-up is considered the power in the outer plates is reduced due to a greater-than-average burn-up rate. In Cycle 6 the plate power distribution is nearly uniform and in Cycle 8 the plate power distribution has inverted, with the inner plates having the greatest relative power. The HEU plate-wise cumulative burnup at EOC is shown in Figure 31 and plate-wise power fraction at EOC is shown in Figure 32. The platewise power fraction as a function of cycle tends to have a negative slope for the first and second plates and a positive slope for the other plates. The cumulative burn-up divided by the power fraction is shown in Figure 33.

Similar results for the LEU case are shown in Figure 34 - Figure 39. The most significant difference between the HEU and LEU results, the plate-wise power distributions, is shown in Figure 35. In the HEU case the plate-wise power distribution is flattened at SU of Cycle 6, but in the LEU case the plate-wise power distribution does not flatten until SU of Cycle 8. This is due to the higher initial fissile loading in the LEU case as well as the build-up of Pu-239 and other actinides. The higher local inventory of fissile material in the LEU case maintains the peak power fraction in the outer plates. The plate-wise burn-up power distribution factors (relative powers) are displayed in tabular form in Appendix C. 


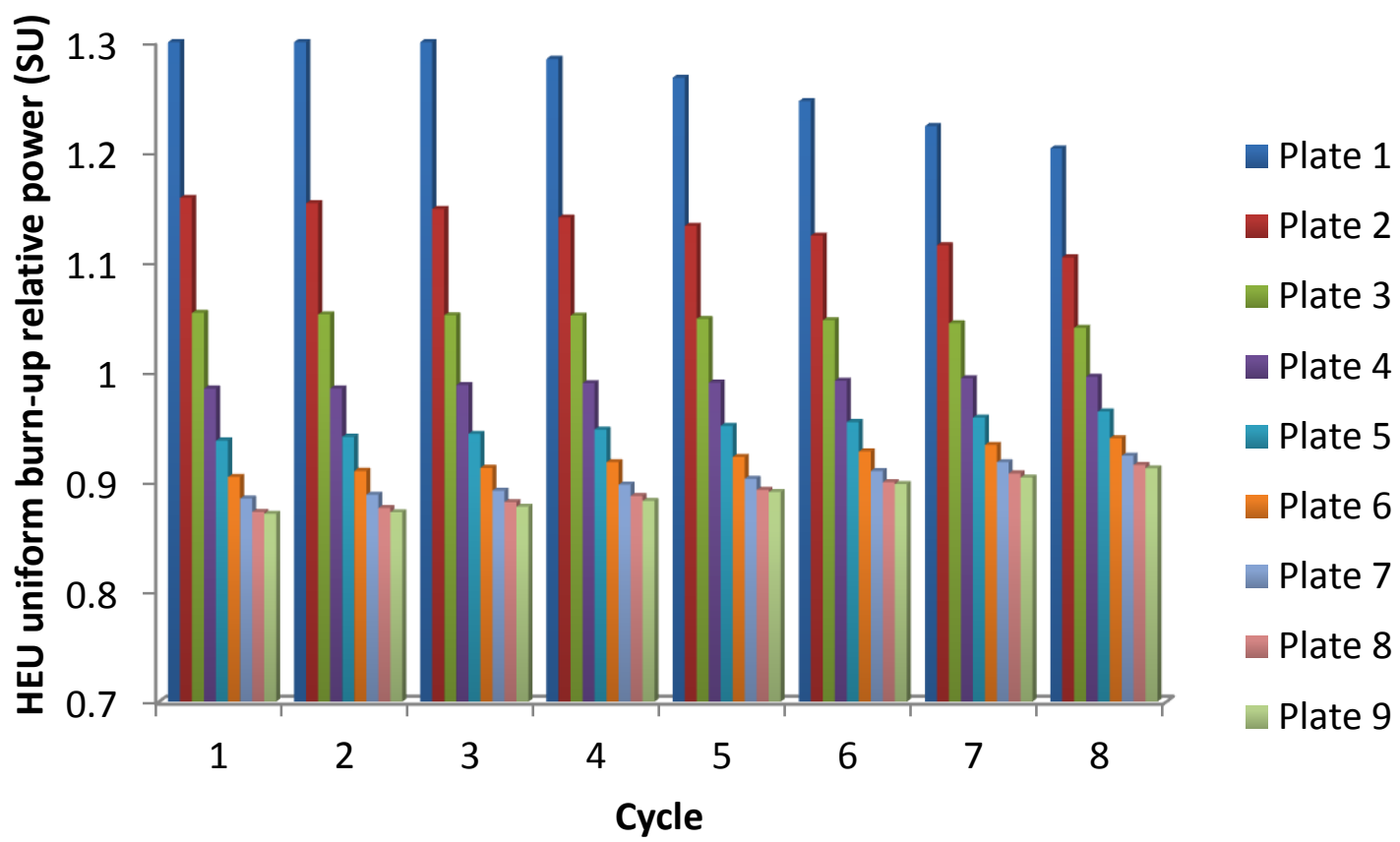

Figure 28 - Single-element HEU plate-wise power distributions assuming uniform burn-up

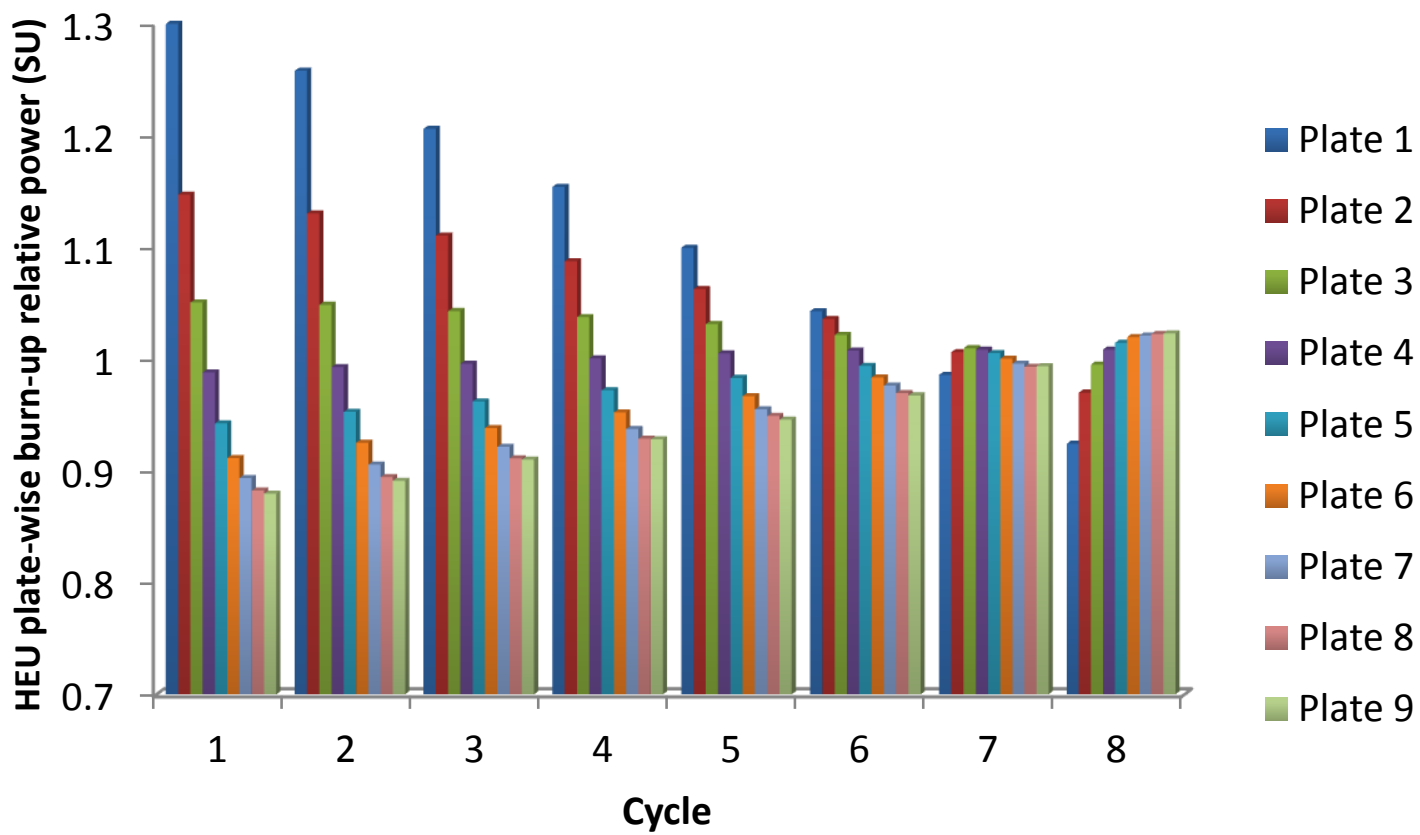

Figure 29 - Single-element HEU plate-wise power distributions assuming plate-wise burn-up 


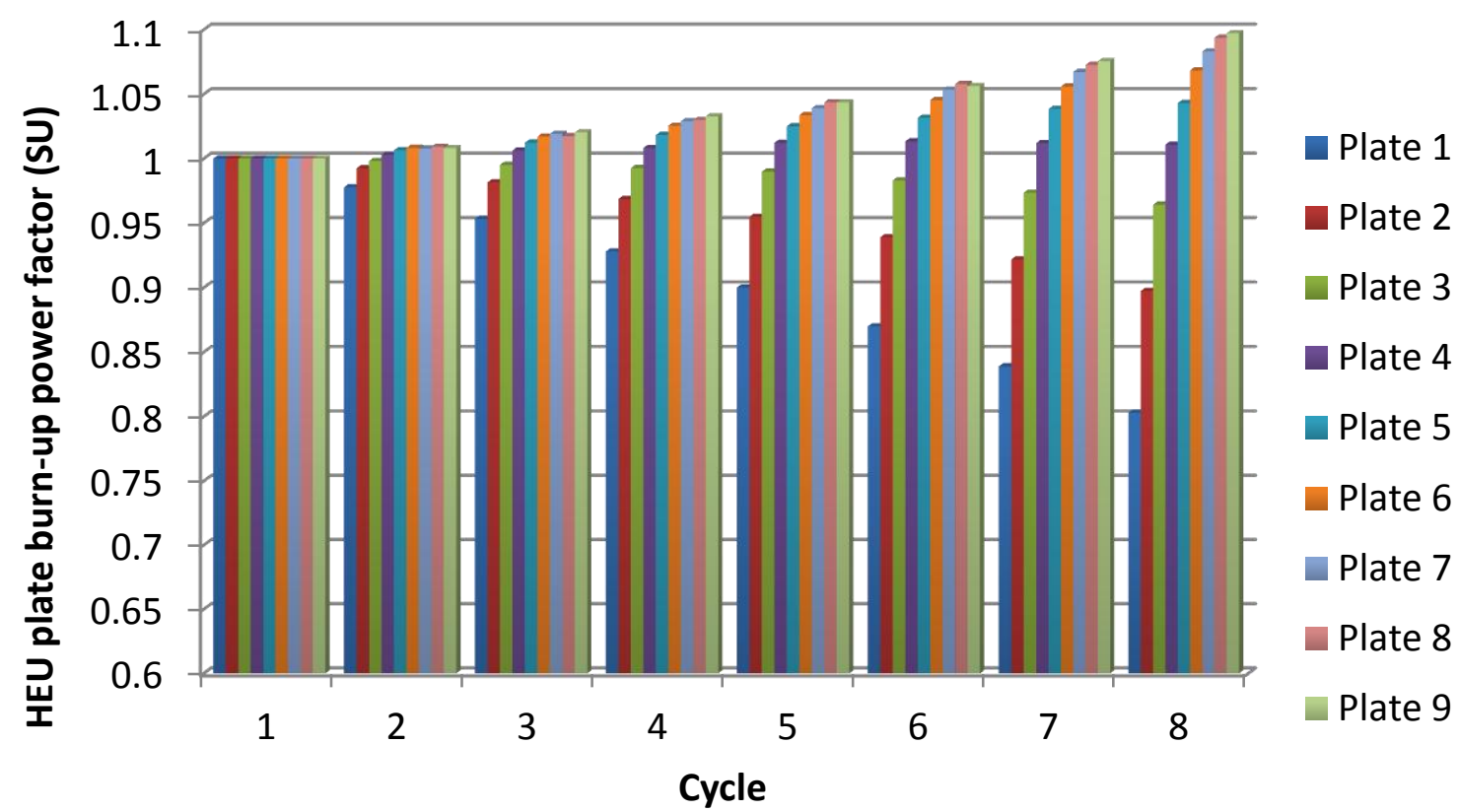

Figure 30 - Single-element HEU plate-wise burn-up factor

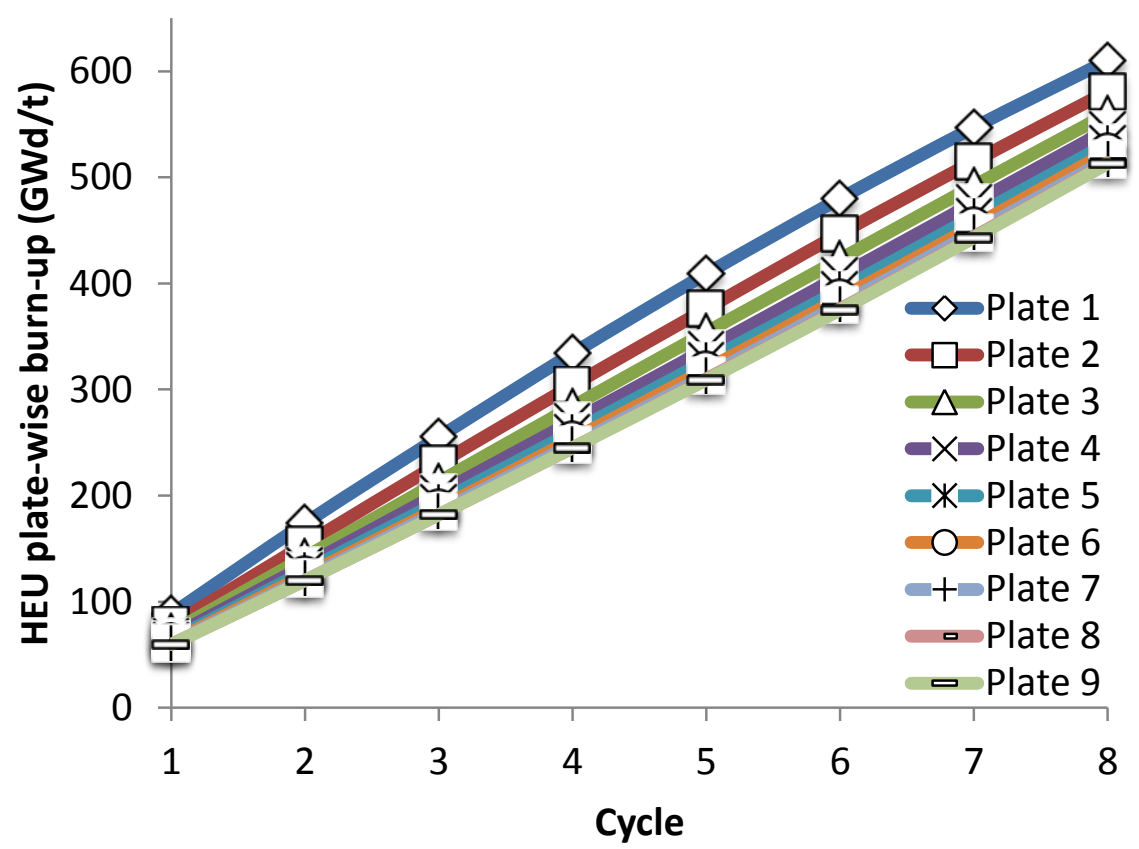

Figure 31 - HEU cumulative plate-wise burn-up at EOC (GWd/t) as a function of cycle 


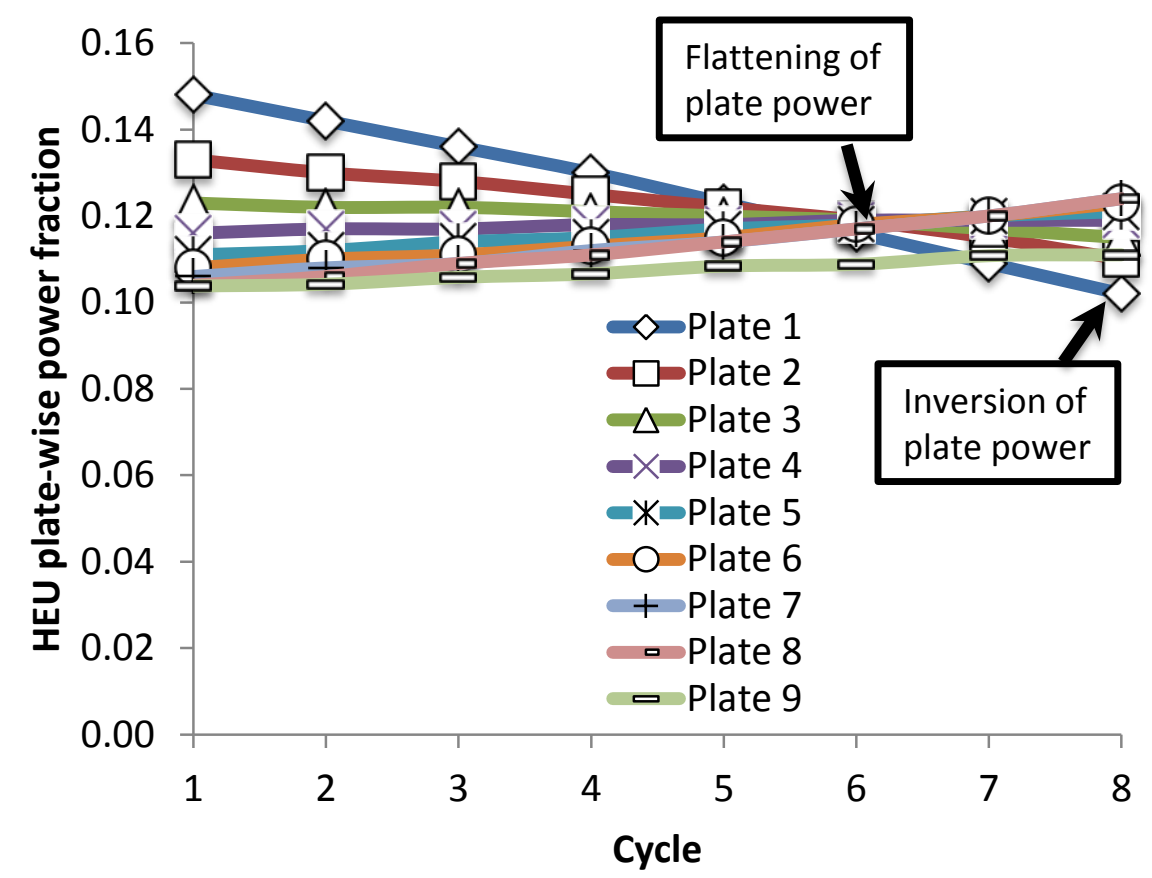

Figure 32 - HEU plate-wise power fraction at EOC as a function of cycle

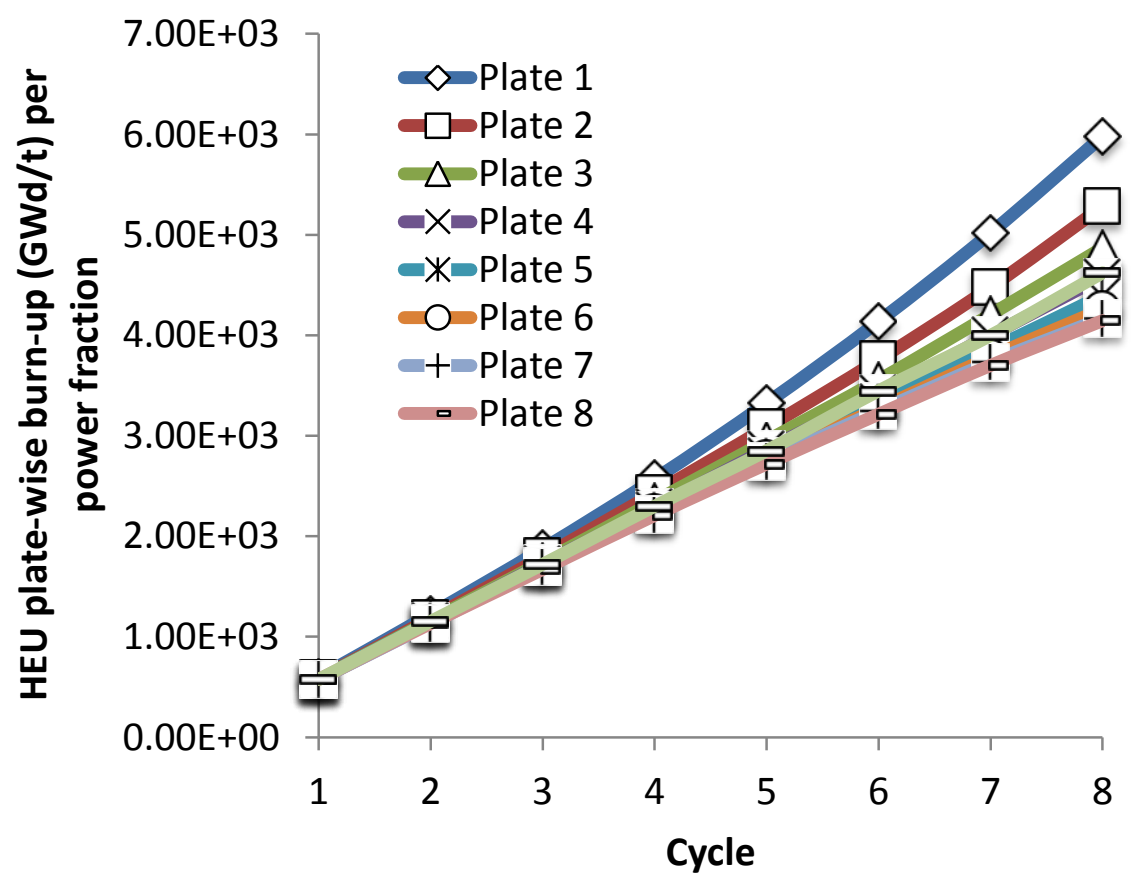

Figure 33 - HEU cumulative burn-up at $\operatorname{EOC}(G W d / t)$ per plate-wise power fraction 


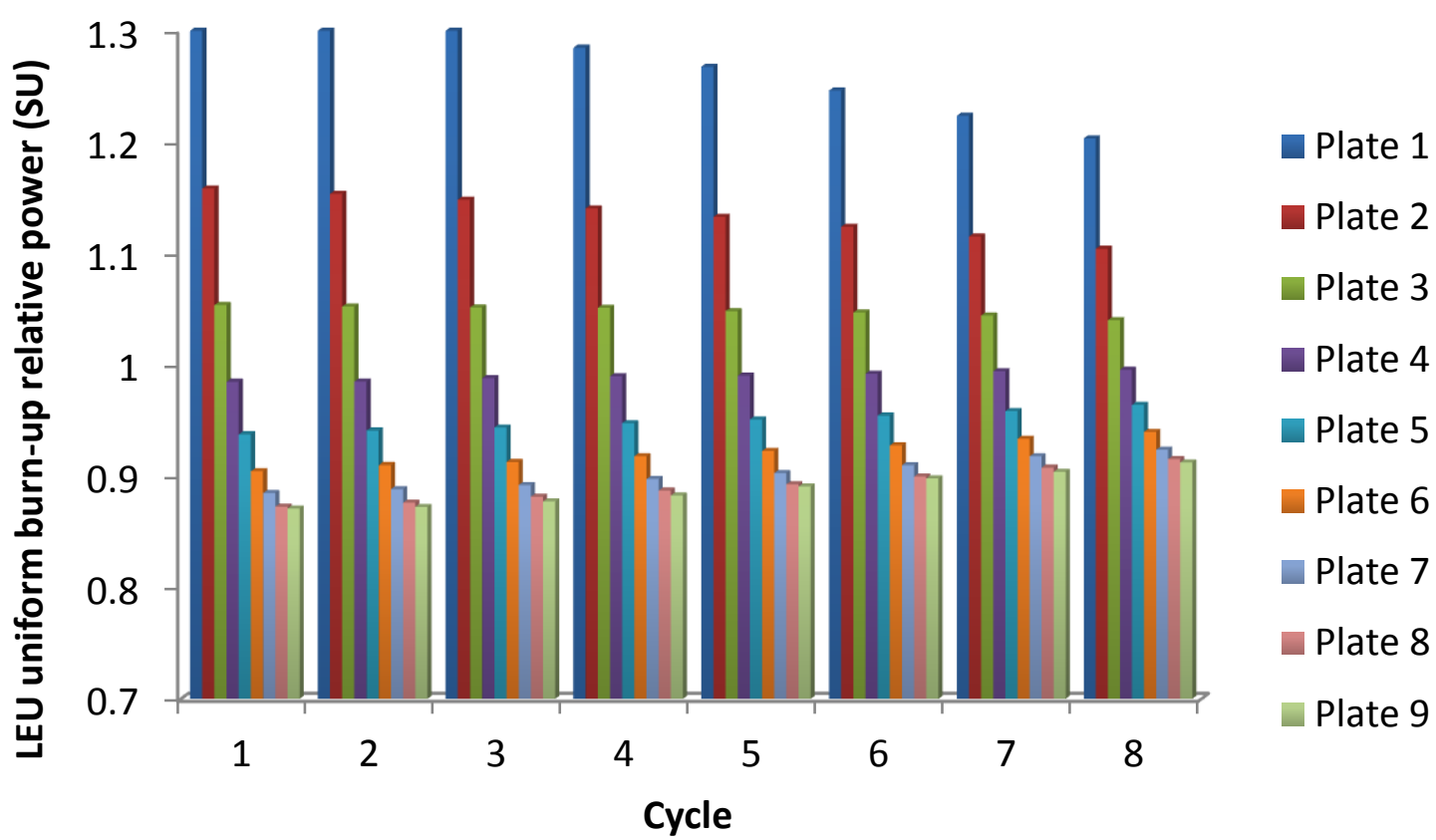

Figure 34 - Single-element LEU plate-wise power distributions assuming uniform burn-up

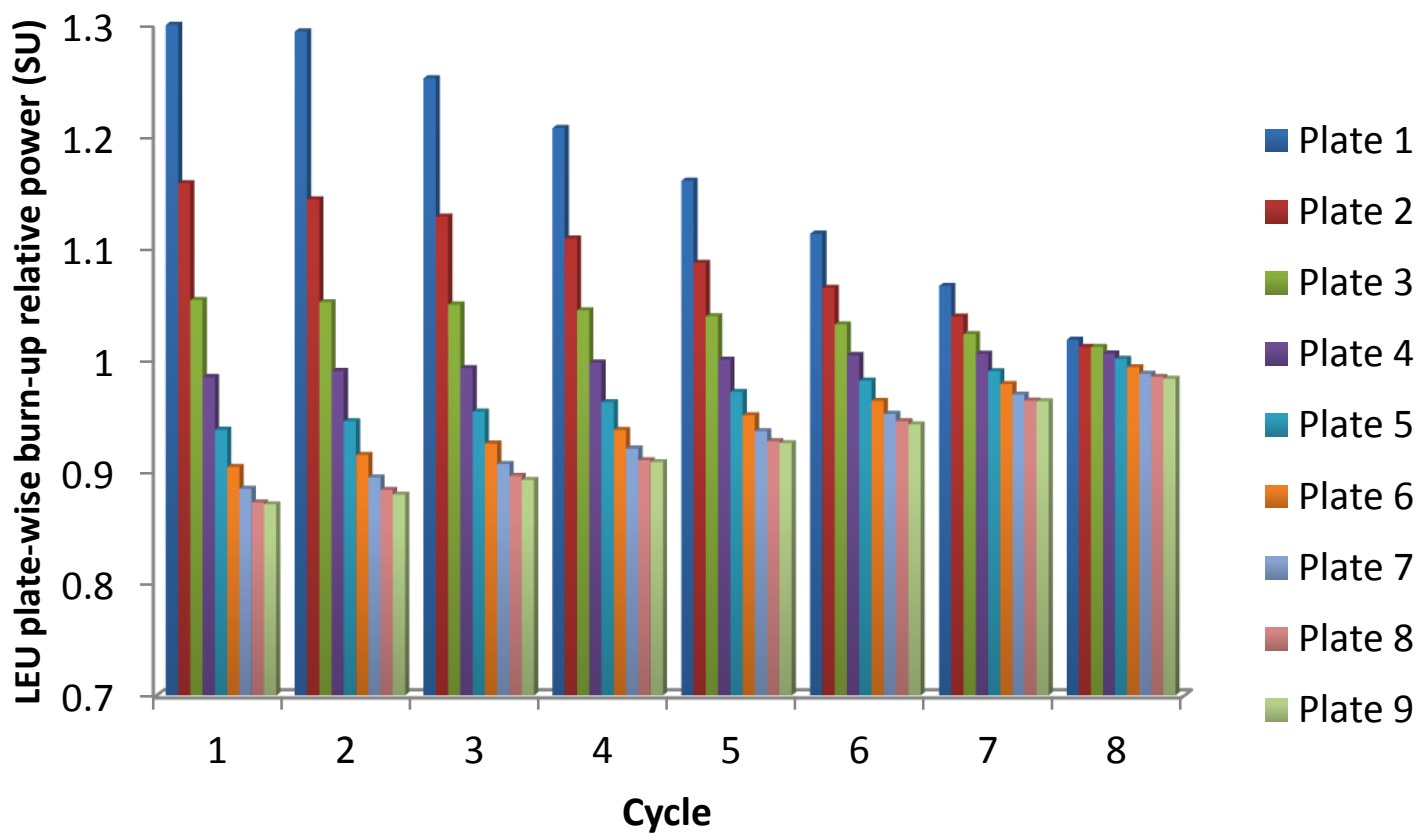

Figure 35 - Single-element LEU plate-wise power distributions assuming plate-wise burn-up 


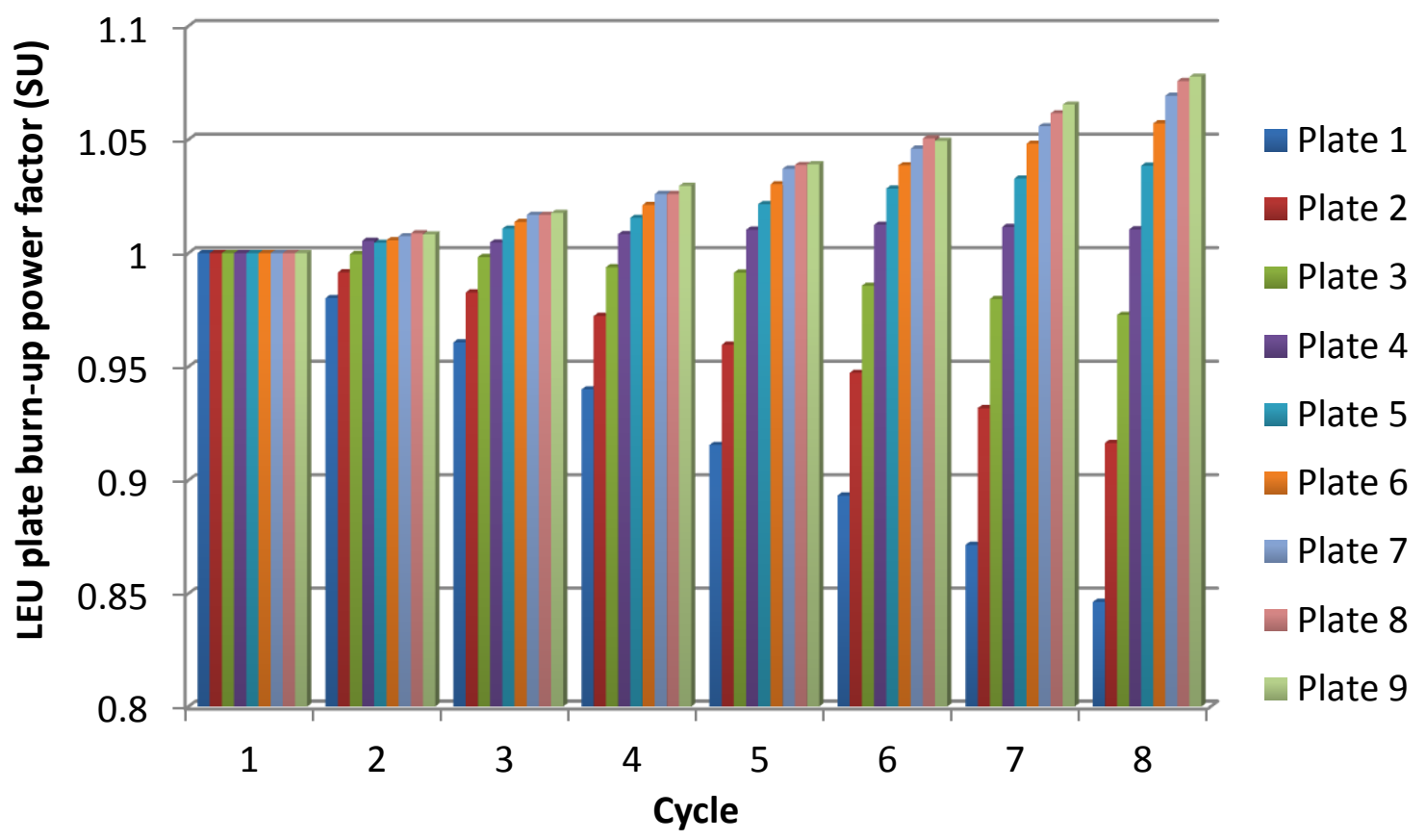

Figure 36 - Single-element LEU plate-wise burn-up factor

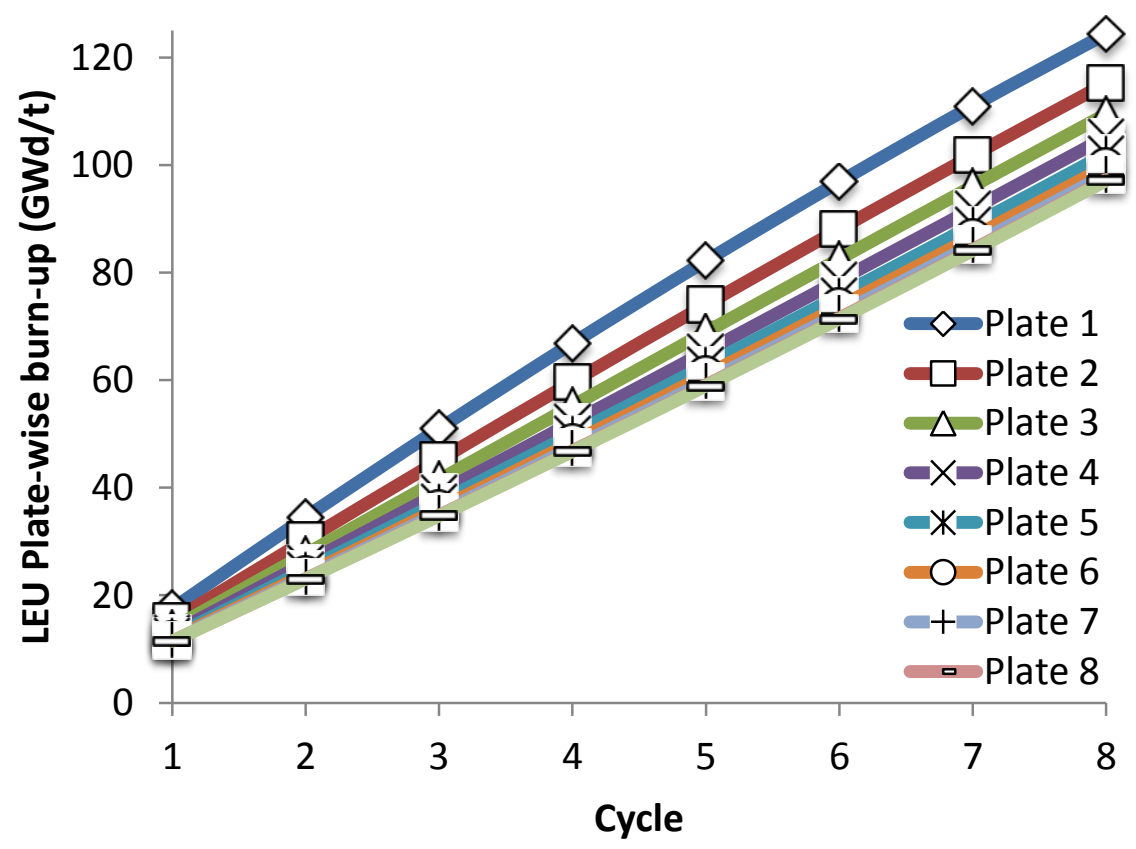

Figure 37 - LEU cumulative plate-wise burn-up at EOC (GWd/t) as a function of cycle 


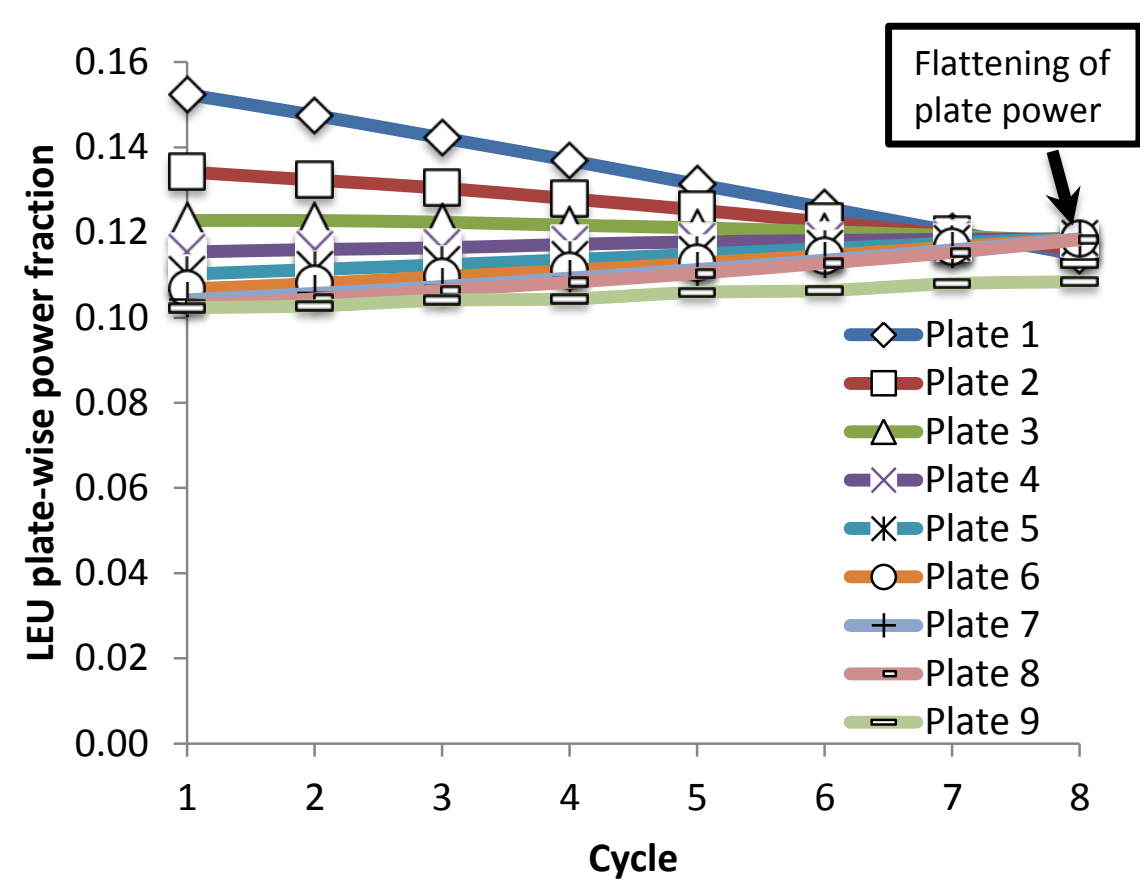

Figure 38 - LEU plate-wise power fraction at EOC as a function of cycle

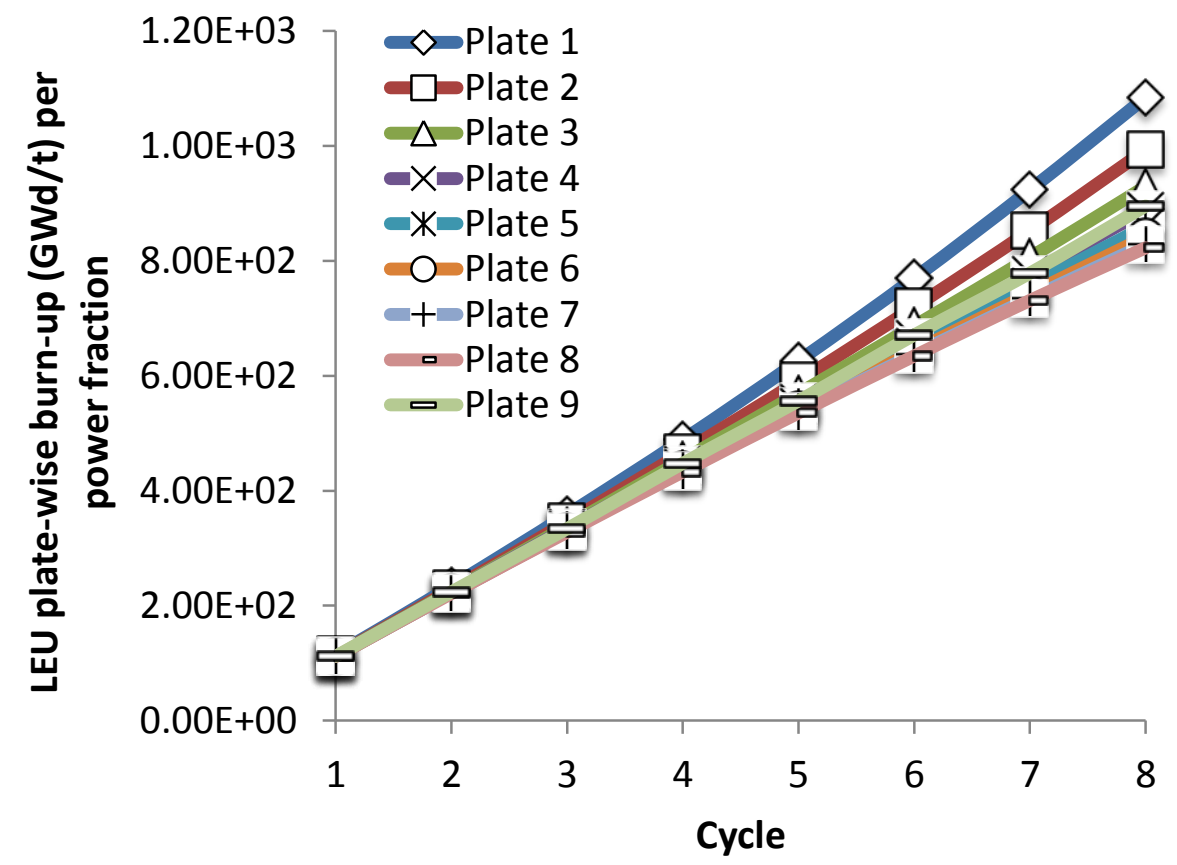

Figure 39 - LEU cumulative burn-up at EOC (GWd/t) per plate-wise power fraction 


\section{Reactivity Effects of Uneven Burn-Up}

In addition to the impact on the power distribution, the uneven burn-up also impacts the reactivity worth of the fuel elements. Assuming uniform burn-up artificially shifts fissile inventory to high importance regions, such as the mid-plane gap or the edges of the fuel elements. The reactivity difference due to treatment of the burn-up distribution is defined in percent millirho ( $\mathrm{pcm})$ as,

$$
\Delta \rho \mathrm{pcm}=10^{5} \times\left(k_{\text {uniform }}-k_{\text {variant }}\right) /\left(k_{\text {uniform }} k_{\text {variant }}\right)
$$

The difference between the infinite lattice reactivity of the uniform and axial burn-up cases is shown in Figure 40. In Figure 40 all of the reactivity differences are calculated at EOC and Cycle 0 is actually SU of Cycle 1. Although the reactivity difference becomes large, it is important to note that this is infinite lattice reactivity and therefore radial leakage is not accounted for. The NBSR is designed to radially stream low-energy neutrons out of the core from the mid-plane gap region, and therefore the radial leakage is very significant in the neutron balance. Thus, full-core calculations are required to quantify the impact of the reactivity bias on the core reactivity. The infinite lattice reactivity difference is most significant in Cycle 6 through Cycle 8, when the axial nodes adjacent to the mid-plane gap are almost totally depleted. The HEU reactivity difference diverges from the LEU reactivity difference in Cycle 6.

The difference between the infinite lattice reactivity of the uniform and plate-wise burn-up cases is shown in Figure 41. The plate-wise burn-up effect on the lattice reactivity is much less significant than the axial effect. The small oscillations in Figure 41 are due to the statistics of the calculation.

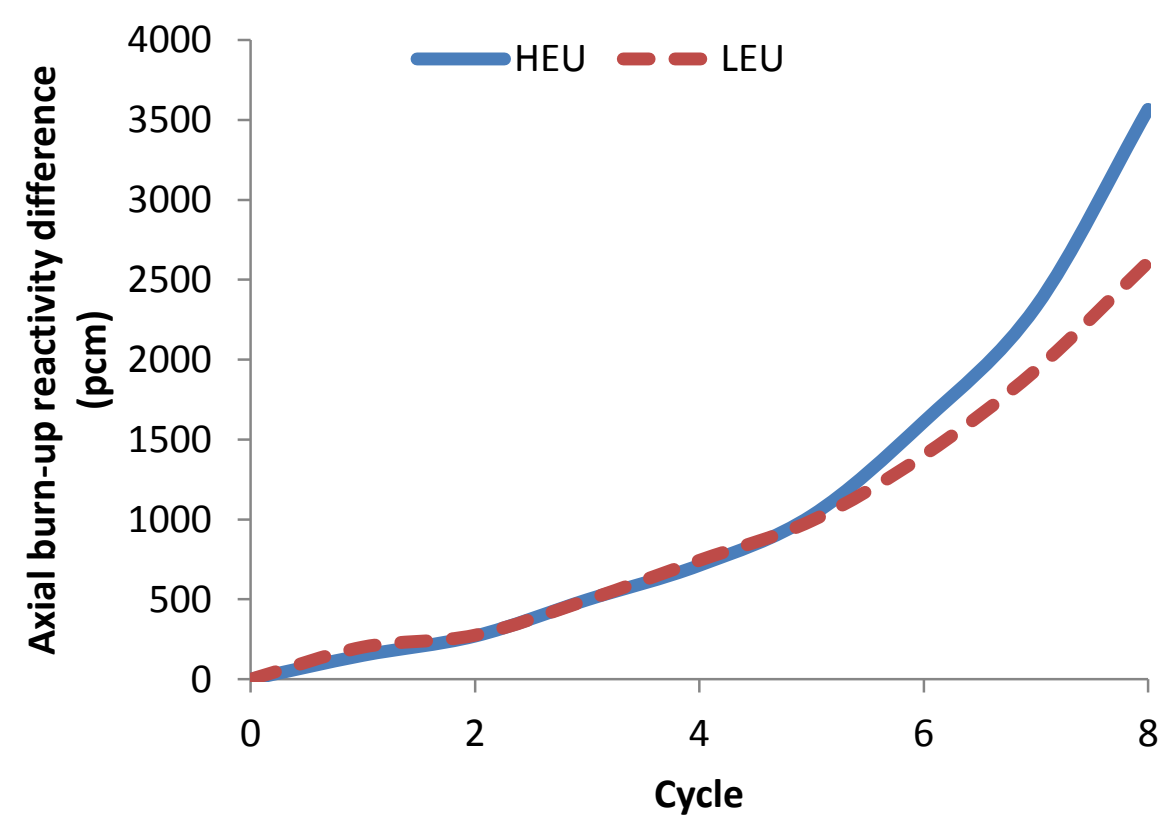

Figure 40 - Reactivity difference of the uniform burn-up case and the axial burn-up case 


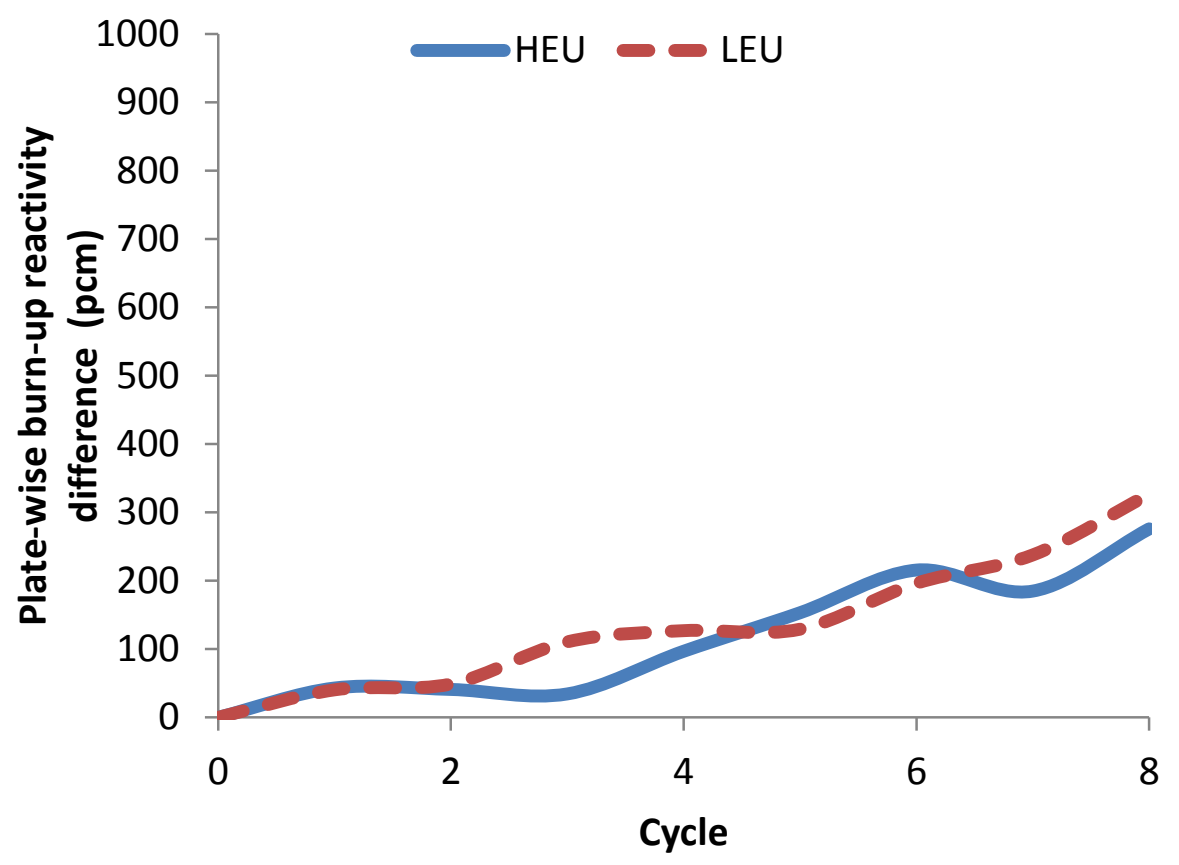

Figure 41 - Reactivity difference of the uniform burn-up case and the plate-wise burn-up case 


\section{Summary and Recommendations}

The effect of axial and plate-wise burn-up on the power distribution in an NBSR fuel element has been studied and compared with results assuming uniform burn-up in a half-element. Results were obtained for both HEU and LEU elements. The study shows how the thermal flux peak in the unfuelled mid-plane gap and the plate-to-plate self-shielding impact the power distribution. The peak relative power of the uniform burn-up cases is always higher than the axial and plate-wise burn-up cases. Furthermore, in Cycle 6 through Cycle 8 the location of the peak relative power is often in a different location for the axial and plate-wise burn-up cases.

For both the HEU and LEU cases the impact of the axial mid-plane gap on the burn-up distribution is greater than the impact of the plate-wise self-shielding. Nevertheless, both effects significantly alter the burn-up and power distributions within the NBSR fuel element. The local burn-up effects are slightly more pronounced for the HEU fuel element. The HEU power distributions, when compared to the LEU power distributions, are more sensitive to both the axial and plate-wise burn-up effects. The LEU element has higher initial loading of fissile material, increased build-up of higher actinides, and greater importance of the self-shielding effects due to absorption in U-238.

Detailed analysis of the burn-up results justifies lumping the majority of the burn-up nodes. However, nodes near thermal flux peaks cannot be realistically lumped. Lumping nodes near thermal flux peaks with dissimilar nodes will result in unrealistic burn-up and power distributions throughout the fuel element. Non-physical lumping of the nodes near thermal flux peaks will also bias the reactivity worth of the fuel element, although the impact of this bias on the full-core reactivity and the fuel cycle length has not been assessed.

There are several potential applications of this work. The single-element results could be utilized to generate burn-up correction factors for the full-core power distributions. These correction factors would be applied to the whole core power distribution as a function of irradiation history, axial location, and plate. Another approach would be to utilize the single-element results to inform the calculation of a new equilibrium core utilizing an improved scheme for lumping the fuel element inventories if more fuel compositions were to be modeled. In this new scheme, the location of the thermal flux peaks inherent in the NBSR fuel element design would be incorporated into the choice of nodes for lumping the fuel element burn-up.

This study ignores the effect of the shim arms, which have significant impact on the local burn-up distribution. In this study the synergistic burn-up of the mid-plane gap and plate-to-plate self-shielding were ignored, and the two effects were isolated by selection of distinct burn-up meshing for each effect. However, in reality the axial and plate-wise burn-up will occur synergistically, further altering the burnup and power distributions. Quantification of these effects could be the focus of future studies. 


\section{References}

[1] A.L. Hanson and D.J. Diamond, "Calculation of Design Parameters for an Equilibrium LEU Core in the NBSR," Brookhaven National Laboratory, Upton, NY, Technical Report September 29, 2011.

[2] D.B. Pelowitz, "MCNPX Users Manual Version 2.7.0," Los Alamos National Laboratory, LA-CP-1100438, 2011.

[3] A.L. Hanson and D.J. Diamond, "Calculation of Design Parameters for the HEU-to-LEU Conversion of the NBSR," Brookhaven National Laboratory, Upton, NY, Technical Report October 29, 2010.

[4] National Institute of Standards and Technology, "Safety Analysis Report (SAR) for License Renewal for the National Institute of Standards and Technology Reactor - NBSR; NBSR-14, Rev. 4," U.S. Department of Commerce, NISTIR 7102, 2010. Note that this is a modified version of the original NBSR-14 issued in 2004.

[5] N.R. Brown, A.L. Hanson, and D.J. Diamond, "Neutron Flux and Energy Spectrum in the NBSR," Brookhaven National Laboratory, Upton, NY, Memo report April 27, 2012.

[6] N.R. Brown, A.L. Hanson, and D.J. Diamond, "Power Peaking in the Converted NBSR," Brookhaven National Laboratory, Upton, NY, Memo report April 16, 2012. 


\section{Appendix A - Discussion of Uneven Burn-Up in the 2010 SAR}

Note: the following material is quoted from Reference [4]. MONTEBURNS is the burn-up calculation tool utilized in the 2010 SAR.

\section{Uneven Burnup Correction of EOC Hot Spot Factors:}

The burnup analysis using MONTEBURNS produces a set of MCNP materials in which the concentrations of ${ }^{235} \mathrm{U}$ are determined from the average fission rates in a pair of fuel elements over the course of each cycle. These materials fill all the fuel meat cells in an element uniformly. It is impossible for MONTEBURNS to generate a sufficient number of MCNP materials to track the uneven burnup within a given fuel element. Since the fission rate at a hot spot may be well over twice the average rate, according to the MCNP power distributions cited above, it is clear that the ${ }^{235} \mathrm{U}$ atom density at a hot spot at EOC will be lower than the average value characteristic of the MCNP material for the element. Because the hot spots are always at the edges of the fuel sections adjacent to the unfueled center, the uneven burnup is compounded cycle after cycle. As a result, the hot spot factors determined from MCNP power distributions will be increasingly distorted, large over-estimates, with each sequential cycle in core. MCNP power distributions in elements burned more than 4 cycles indicate hot spots (near the unfueled region) where there would be no fuel remaining if the power distributions in earlier cycles were correct.

A correction factor for uneven burnup can be estimated by calculating the ${ }^{235} \mathrm{U}$ density at the hot spot at EOC, and its ratio to the EOC material average density. Since the neutron flux in the unfueled region is nearly constant through a cycle, the fission rate is proportional to the estimated ${ }^{235} \mathrm{U}$ atom density. The core average fission rate is obtained from the fact that $667 \mathrm{~kW}$ is produced per element in $296 \mathrm{~cm}^{3}$. Since approximately $3.1 \times 10^{10}$ fissions/sec is required per watt, the average fission rate is $7.0 \times 10^{13}$ fissions $/ \mathrm{cm}^{3} / \mathrm{s}$. The rate of consumption of ${ }^{235} \mathrm{U}$ is 1.17 times the fission rate, or $7.1 \times 10^{18}$ absorptions $/ \mathrm{cm}^{3} /$ day. We define ' $\mathrm{a}$ ' as the fractional daily consumption rate, which for a fresh fuel element is given by

$$
\begin{gathered}
\mathrm{a}=\left(7.1 \times 10^{18} \text { absorptions } / \mathrm{cm}^{3} / \text { day }\right) /\left(3.03 \times 10^{21} \text { atoms } / \mathrm{cm}^{3}\right) \\
\mathrm{a}=0.0023 \mathrm{day}^{-1} .
\end{gathered}
$$

At any time, $t$, the loss rate is

$$
\mathrm{dN} / \mathrm{dt}=-\mathrm{a} \mathrm{N}(\mathrm{t}) .
$$

The solution is the atom density as a function of time

$$
\mathrm{N}_{35}(\mathrm{t})=\mathrm{N}_{\mathrm{SU}} \exp (-\mathrm{at})
$$

where, $\mathrm{N}_{\mathrm{SU}}$ is the ${ }^{235} \mathrm{U}$ atom density at startup.

For a hot spot with an average peaking factor of $\langle\mathrm{pf}\rangle$ over a 38-day cycle, 


$$
\mathrm{N}_{\mathrm{EOC}}=\mathrm{N}_{\mathrm{SU}} \exp (-0.088<\mathrm{pf}>), \text { where } \mathrm{a}^{*} \mathrm{t}=0.088
$$

From the MCNP fuel constituents, the EOC density is

$$
\mathrm{N}_{\mathrm{EOC}, \mathrm{MCNP}}=\left(\mathrm{w}_{\mathrm{EOC}} / \mathrm{w}_{\mathrm{SU}}\right) \mathrm{N}_{\mathrm{SU}},
$$

where the w's are the weight fractions of ${ }^{235} \mathrm{U}$ in the SU and EOC MCNP materials.

The ratio of the hot spot $\mathrm{U}$ density to the MCNP material composition will be the correction factor for the EOC peaking factor:

$$
\eta=\mathrm{N}_{\mathrm{EOC}} / \mathrm{N}_{\mathrm{EOC}, \mathrm{MCNP}}=\left(\mathrm{w}_{\mathrm{SU}} / \mathrm{w}_{\mathrm{EOC}}\right) \exp (-0.088<\mathrm{pf}>) .
$$

For example, the peaking factors for both fuel sections of A-4 for the SU and EOC cores are 2.485, 2.092, 2.254, and 2.175, so $\left\langle\mathrm{pf}>=2.25\right.$. Its ${ }^{235} \mathrm{U}$ weight fractions are $\mathrm{w}_{\mathrm{SU}}=0.3274$ and $\mathrm{w}_{\mathrm{EOC}}=0.3007$, and the hot spot correction factor is

$$
\eta_{\mathrm{A}-4}=(0.3274 / 0.3007) \exp [(-0.088)(2.25)]=(1.09) \exp [(-0.088)(2.25)]=0.89
$$

The fuel density is only $89 \%$ of the MCNP value at the hot spots of A-4 at EOC, and, therefore, the EOC hot spot peaking factors are reduced by this factor. For element M-4, the factor is 0.90 , and the hot spot factors for $\mathrm{H}-1$ were reduced in the SU core because the M-4 element is moved to $\mathrm{H}-1$ for the start of the following cycle...

Uneven burnup, cycle after cycle, has a profound effect on the power distribution within the fuel elements. Hot spot and axial peaking factors are reduced as the fuel on the edges of the elements is preferentially consumed. As the heat generation moves toward the interior of the fuel element it is more evenly distributed among the plates, and subsequent hot spots and hot channels are never as large as the MCNP calculated results. Values for $\eta$ in subsequent cycles have been estimated, and new peaking factors generated....

The correction factors used ... are as follows: 0.9 , for a one-cycle correction, $(0.92)^{2}$ for the two-cycle correction, and $(0.92)^{3}$ for the three (or more) cycle correction. The hot channel factors were not changed: this is conservative, resulting in an overestimate of the heat deposited in those channels. 


\section{Appendix B - Axial Burn-Up Power Distribution Factors}

HEU axial burn-up power distribution factors at SU

\begin{tabular}{|c|c|c|c|c|c|c|c|c|c|c|}
\hline \multicolumn{2}{|c|}{ Axial Height $(\mathrm{cm})$} & Cycle 1 & Cycle 2 & Cycle 3 & Cycle 4 & Cycle 5 & Cycle 6 & Cycle 7 & Cycle 8 & End-of-life \\
\hline \pm & 35.83 & 1.00 & 1.00 & 1.01 & 1.01 & 1.02 & 1.03 & 1.06 & 1.08 & 1.12 \\
\hline \pm & 33.84 & 1.00 & 1.02 & 1.03 & 1.04 & 1.07 & 1.09 & 1.14 & 1.19 & 1.27 \\
\hline \pm & 31.84 & 1.00 & 1.01 & 1.03 & 1.05 & 1.07 & 1.11 & 1.15 & 1.20 & 1.29 \\
\hline \pm & 29.85 & 1.00 & 1.01 & 1.02 & 1.05 & 1.07 & 1.10 & 1.14 & 1.19 & 1.28 \\
\hline \pm & 27.85 & 1.00 & 1.01 & 1.03 & 1.04 & 1.07 & 1.09 & 1.13 & 1.18 & 1.25 \\
\hline \pm & 25.85 & 1.00 & 1.01 & 1.02 & 1.04 & 1.06 & 1.09 & 1.12 & 1.16 & 1.22 \\
\hline \pm & 23.86 & 1.00 & 1.01 & 1.02 & 1.03 & 1.05 & 1.07 & 1.10 & 1.14 & 1.19 \\
\hline \pm & 21.86 & 1.00 & 1.01 & 1.02 & 1.04 & 1.05 & 1.06 & 1.09 & 1.11 & 1.14 \\
\hline \pm & 19.87 & 1.00 & 1.01 & 1.02 & 1.03 & 1.03 & 1.05 & 1.06 & 1.07 & 1.08 \\
\hline \pm & 17.87 & 1.00 & 1.00 & 1.01 & 1.02 & 1.03 & 1.03 & 1.04 & 1.03 & 1.02 \\
\hline \pm & 15.88 & 1.00 & 1.00 & 1.01 & 1.01 & 1.01 & 1.01 & 1.00 & 0.98 & 0.93 \\
\hline \pm & 13.88 & 1.00 & 1.00 & 1.00 & 0.99 & 0.99 & 0.97 & 0.94 & 0.90 & 0.82 \\
\hline \pm & 11.88 & 1.00 & 0.99 & 0.98 & 0.96 & 0.94 & 0.89 & 0.84 & 0.76 & 0.65 \\
\hline \pm & 9.89 & 1.00 & 0.96 & 0.91 & 0.85 & 0.78 & 0.71 & 0.62 & 0.52 & 0.41 \\
\hline
\end{tabular}


LEU axial burn-up power distribution factors at SU

\begin{tabular}{|c|c|c|c|c|c|c|c|c|c|c|}
\hline \multicolumn{2}{|c|}{ Axial Height $(\mathrm{cm})$} & Cycle 1 & Cycle 2 & Cycle 3 & Cycle 4 & Cycle 5 & Cycle 6 & Cycle 7 & Cycle 8 & End-of-life \\
\hline \pm & 35.83 & 1.00 & 1.00 & 1.00 & 1.01 & 1.01 & 1.03 & 1.03 & 1.04 & 1.06 \\
\hline \pm & 33.84 & 1.00 & 1.01 & 1.02 & 1.04 & 1.06 & 1.09 & 1.11 & 1.14 & 1.17 \\
\hline \pm & 31.84 & 1.00 & 1.02 & 1.03 & 1.04 & 1.06 & 1.09 & 1.12 & 1.15 & 1.20 \\
\hline \pm & 29.85 & 1.00 & 1.02 & 1.02 & 1.04 & 1.06 & 1.08 & 1.11 & 1.14 & 1.20 \\
\hline \pm & 27.85 & 1.00 & 1.01 & 1.02 & 1.04 & 1.06 & 1.08 & 1.11 & 1.14 & 1.18 \\
\hline \pm & 25.85 & 1.00 & 1.01 & 1.02 & 1.04 & 1.05 & 1.07 & 1.10 & 1.13 & 1.16 \\
\hline \pm & 23.86 & 1.00 & 1.01 & 1.02 & 1.03 & 1.05 & 1.06 & 1.09 & 1.11 & 1.14 \\
\hline \pm & 21.86 & 1.00 & 1.00 & 1.02 & 1.03 & 1.04 & 1.05 & 1.08 & 1.10 & 1.12 \\
\hline \pm & 19.87 & 1.00 & 1.00 & 1.02 & 1.02 & 1.03 & 1.05 & 1.06 & 1.07 & 1.09 \\
\hline \pm & 17.87 & 1.00 & 1.00 & 1.01 & 1.02 & 1.03 & 1.03 & 1.04 & 1.04 & 1.05 \\
\hline \pm & 15.88 & 1.00 & 1.00 & 1.01 & 1.01 & 1.01 & 1.01 & 1.01 & 1.00 & 0.99 \\
\hline \pm & 13.88 & 1.00 & 1.00 & 1.00 & 0.99 & 0.99 & 0.98 & 0.97 & 0.94 & 0.91 \\
\hline \pm & 11.88 & 1.00 & 0.99 & 0.98 & 0.97 & 0.95 & 0.92 & 0.88 & 0.84 & 0.77 \\
\hline \pm & 9.89 & 1.00 & 0.97 & 0.92 & 0.87 & 0.82 & 0.75 & 0.68 & 0.61 & 0.54 \\
\hline
\end{tabular}




\section{Appendix C - Plate-Wise Burn-Up Power Distribution Factors}

HEU plate-wise burn-up power distribution factors at SU

\begin{tabular}{|c|c|c|c|c|c|c|c|c|c|}
\hline & Cycle 1 & Cycle 2 & Cycle 3 & Cycle 4 & Cycle 5 & Cycle 6 & Cycle 7 & Cycle 8 & End-of-life \\
\hline Plate 1 & 1.00 & 0.98 & 0.95 & 0.93 & 0.90 & 0.87 & 0.84 & 0.80 & 0.77 \\
\hline Plate 2 & 1.00 & 0.99 & 0.98 & 0.97 & 0.95 & 0.94 & 0.92 & 0.90 & 0.87 \\
\hline Plate 3 & 1.00 & 1.00 & 1.00 & 0.99 & 0.99 & 0.98 & 0.97 & 0.96 & 0.95 \\
\hline Plate 4 & 1.00 & 1.00 & 1.01 & 1.01 & 1.01 & 1.01 & 1.01 & 1.01 & 1.01 \\
\hline Plate 5 & 1.00 & 1.01 & 1.01 & 1.02 & 1.03 & 1.03 & 1.04 & 1.04 & 1.05 \\
\hline Plate 6 & 1.00 & 1.01 & 1.02 & 1.03 & 1.03 & 1.05 & 1.06 & 1.07 & 1.08 \\
\hline Plate 7 & 1.00 & 1.01 & 1.02 & 1.03 & 1.04 & 1.05 & 1.07 & 1.08 & 1.10 \\
\hline Plate 8 & 1.00 & 1.01 & 1.02 & 1.03 & 1.04 & 1.06 & 1.07 & 1.09 & 1.11 \\
\hline Plate 9 & 1.00 & 1.01 & 1.02 & 1.03 & 1.04 & 1.06 & 1.08 & 1.10 & 1.12 \\
\hline
\end{tabular}

LEU plate-wise burn-up power distribution factors at SU

\begin{tabular}{|c|c|c|c|c|c|c|c|c|c|}
\hline & Cycle 1 & Cycle 2 & Cycle 3 & Cycle 4 & Cycle 5 & Cycle 6 & Cycle 7 & Cycle 8 & End-of-life \\
\hline Plate 1 & 1.00 & 0.98 & 0.96 & 0.94 & 0.92 & 0.89 & 0.87 & 0.85 & 0.82 \\
\hline Plate 2 & 1.00 & 0.99 & 0.98 & 0.97 & 0.96 & 0.95 & 0.93 & 0.92 & 0.90 \\
\hline Plate 3 & 1.00 & 1.00 & 1.00 & 0.99 & 0.99 & 0.99 & 0.98 & 0.97 & 0.96 \\
\hline Plate 4 & 1.00 & 1.01 & 1.00 & 1.01 & 1.01 & 1.01 & 1.01 & 1.01 & 1.01 \\
\hline Plate 5 & 1.00 & 1.00 & 1.01 & 1.02 & 1.02 & 1.03 & 1.03 & 1.04 & 1.04 \\
\hline Plate 6 & 1.00 & 1.01 & 1.01 & 1.02 & 1.03 & 1.04 & 1.05 & 1.06 & 1.07 \\
\hline Plate 7 & 1.00 & 1.01 & 1.02 & 1.03 & 1.04 & 1.05 & 1.06 & 1.07 & 1.08 \\
\hline Plate 8 & 1.00 & 1.01 & 1.02 & 1.03 & 1.04 & 1.05 & 1.06 & 1.08 & 1.09 \\
\hline Plate 9 & 1.00 & 1.01 & 1.02 & 1.03 & 1.04 & 1.05 & 1.07 & 1.08 & 1.09 \\
\hline
\end{tabular}

